\title{
Mechanical characterization of wood: An integrative approach ranging from nanoscale to structure
}

\author{
K. de Borst ${ }^{1 \mathrm{a}}$, C. Jenkel ${ }^{2 \mathrm{c}}, \mathrm{C}$. Montero ${ }^{3 \mathrm{~b}}$, J. Colmars ${ }^{4 b}$, J. Gril ${ }^{5 b}$, M. Kaliske ${ }^{6 c}$ \\ and J. Eberhardsteiner ${ }^{7 a}$
}

article in press as: de Borst $\mathrm{K}$ et al. Mechanical characterization of wood: An integrative approach ranging from nanoscale to structure. Comput Struct (2012), http://dx.doi.org/10.1016/j.compstruc.2012.11.019

${ }^{a}$ Vienna University of Technology , Institute for Mechanics of Materials and Structures , Karlsplatz 13/202, 1040 Vienna, Austria ,

b Université Montpellier 2, CNRS, Laboratoire de Mécanique et Génie Civil (LMGC), CC048 - Place Eugène Bataillon, 34095 Montpellier, France,

c Technische Universität Dresden , Institute for Structural Analysis , Nürnberger Straße 31a, D-01062

Dresden, Germany ,

\begin{abstract}
Wood is enjoying increasing popularity in the building sector. In order to fully exploit the potential of this material, particularly in two and three-dimensional structures, improved knowledge of the mechanical behavior of the material and more complex constitutive models are required. We herein present a holistic approach to mechanical material modeling of wood, including a multitude of length scales as well as computational and experimental efforts. This allows to resolve the microstructural origin of the macro- scopic material behavior and to finally apply the gained knowledge to structural applications in a timber engineering framework. Focusing on elastoplasticity and viscoelasticity, exemplary results of the per- formed investigations are presented and their interrelations discussed. Regarding computational approaches, presented developments include multiscale models for prediction of elastic limit states and creep compliances of wood, macroscopic phenomenological models for wood plasticity and the time and moisture-dependent behavior, and their applications to investigations of dowel-joints and glued- laminated timber beams. Accompanying experiments provided additional input data for the computa- tional analyses, therewith completing the set of material properties predicted by the multiscale models. Moreover, they served as the reference basis for model validation at both the material and the structural scale.
\end{abstract}

\section{INTRODUCTION}

Wood is one of the oldest construction materials known to man. Over thousands of years it has been mainly used in a craft framework, so that current design rules are often based on experience and tradition. In order to exploit the extraordinary ecological potential of this material in terms of making it a mass building material, its structural use also in an industrial framework has to be further enabled and extended. This requires powerful material models. Modern timber

\footnotetext{
${ }^{1}$ Present address: University of Glasgow, School of Engineering, Rankine Building, Glasgow G12 8LT, United Kingdom. Tel.: +44 141330 5919; fax: +44 141330 4557, email : karin.deborst@glasgow.ac.uk

${ }^{2}$ email : christian.jenkel@tu-dresden.de

${ }^{3}$ email : cedric.montero@univ-montp2.fr

${ }^{4}$ email : julien.colmars@imelavi.fr

${ }^{5}$ email : joseph.gril@univ-montp2.fr

${ }^{6}$ email : michael.kaliske@tu-dresden.de

${ }^{7}$ Corresponding author. Tel.: +43 158801 20212; fax: +43 158801 20299, email : josef.eberhardsteiner@tuwien.ac.at
} 
constructions are characterized by increasing demand of two and three-dimensional bearing components. Dimensioning and design of such sophisticated structures require powerful material models for numerical simulation tools such as the finite element method. Three-dimensional formulations accounting for the material anisotropy and describing the material beyond linear elasticity are needed, thereby considering for example the possibility of plastic deformations, cracking, and viscoelastic effects.

Moreover, the large variability of the macroscopic material properties has to be understood and suitably described in order to prevent the need for sizable safety factors, resulting in an uneconomic over-dimensioning of timber members in standard applications. Such an understanding and an appropriate resolution of the origin of the macroscopically observed material behavior require consideration of the hierarchical microstructure of the material. The link between microstructural characteristics of individual wood specimens and corresponding macroscopic characteristics can be established by means of homogenization techniques. Multiscale models provide consistent and accurate sets of macroscopic properties of wood in a fully three-dimensional and orthotropic framework. Thus, they are highly valuable for structural simulations, whose predictive and also descriptive capabilities are currently often limited by the lack of suitable input data or the poor accuracy of available data. Also various couplings, e.g. between moisture transport and mechanical behavior, are suitably captured by these models.

Only a dual approach, combining micromechanical models with powerful numerical algorithms for simulations at structural scale and, thus, spanning all relevant length scales from nanometers to meters, provides the necessary strong basis for modern timber engineering and enables accurate and reliable analysis of wood-based structures and elements. Besides supporting structural analyses and background calculations for standardization, this combination is also expected to contribute to the optimization of production processes such as wood drying. In order to derive a proper understanding of the material behavior, to identify material parameters, and to validate the obtained material models at various length scales, experimental investigations are obligatory and an integral part of each step of the model development.

This paper demonstrates the realization of a holistic approach to material modeling, including a multitude of length scales as well as computational and experimental efforts, taking two characteristic aspects of the mechanical material behavior as examples: elastoplasticity and viscoelasticity, considering also effects upon changing environmental conditions. Table 1 provides an overview of the developments in relation to these two examples and also serves as outline of the paper. Although the presented approaches are applicable to arbitrary wood tissues, the focus is placed on mainly (anatomically simpler) softwood herein for reasons of simplicity and clarity. For elaborate reviews of the state-of-the-art in these fields, we refer to the cited specialized papers by the authors. Particular emphasis is laid on application examples of the developed material models in a timber engineering framework.

First, elastoplasticity will be treated. The material behavior of wood in the small strain regime can be described as being linear-elastic (Gibson and Ashby, 2001). A high pressure loading will lead to ductile failure (Gibson and Ashby, 2001). Herein, we briefly discuss microscale processes which might initiate macroscale failure and show the description of an exemplary microscale failure mode in the framework of multiscale models. The resulting estimates of elastic limit states, which are derived from microscale strength properties, serve as the basis for determination of parameters of a macroscopic plasticity model. The formulation of the model and its implementation in a finite element code are sketched next. Finally, its application to the numerical simulation of the mechanical behavior of a steel-to- timber dowel-type connection demonstrates the capability of the simulation tool in a practical engineering context. Experimental validation rests upon a series of tension tests on single dowel connections. 
Secondly, the focus is placed on viscoelasticity. As an example of microscale experimental investigations, measurements of the crystal strain in cellulose during creep are presented. A multiscale model is again employed in order to link microscale creep mechanisms to corresponding macroscopic creep compliances. Tests on macroscopic samples provide additional information about influences of changing moisture content on the deformations under continuous mechanical load. The model estimates and test results can be employed for determination of material parameters of a generalized Kelvin-Voigt model, which is well-suited for describing the viscoelastic behavior in the framework of numerical simulations by means of the finite element method. As an example application, the relaxation of production stresses in a glulam beam is examined.

Finally, the paper is summarized and conclusions are drawn. The benefits and advantages of such a comprehensive approach are sketched, but also required improvements in the future are discussed.

Most of the presented developments were established in the framework of the project 'MechWood - Mechanical characterization of wood for knowledge-based timber industry', which was launched and partially funded within the initiative 'Building With Wood' by the European Confederation of Woodworking Industries (CEI-Bois).

Table 1: Overview of developments at different length scales and with different approaches

\begin{tabular}{|c|c|c|c|}
\hline Elastoplasticity & Microscale & Macroscale & Structural scale \\
\hline Experimental & $\begin{array}{l}\text { Identification of } \\
\text { microscale fail- } \\
\text { ure mechanisms } \\
\text { from various test } \\
\text { data }\end{array}$ & $\begin{array}{l}\text { Mechanical tests } \\
\text { with different } \\
\text { biaxial loading } \\
\text { states }\end{array}$ & $\begin{array}{l}\text { Tension tests on } \\
\text { dowel-type con- } \\
\text { nections loaded } \\
\text { parallel to the } \\
\text { grain }\end{array}$ \\
\hline Computational & $\begin{array}{l}\text { Multiscale } \\
\text { model for elastic } \\
\text { limit states }\end{array}$ & $\begin{array}{l}\text { Multi-surface } \\
\text { plasticity model } \\
\text { in a finite } \\
\text { element environ- } \\
\text { ment }\end{array}$ & $\begin{array}{l}\text { Numerical } \\
\text { simulations of } \\
\text { elastoplastic } \\
\text { behavior } \\
\text { dowel-type } \\
\text { connections }\end{array}$ \\
\hline Viscoelasticity & Microscale & Macroscale & Structural scale \\
\hline Experimental & $\begin{array}{l}\text { Determination } \\
\text { of nanoscopic } \\
\text { crystal strain } \\
\text { during creep by } \\
\text { X-ray diffraction }\end{array}$ & $\begin{array}{l}\text { Long-term creep } \\
\text { and recovery } \\
\text { tests with vary- } \\
\text { ing loading } \\
\text { histories }\end{array}$ & - \\
\hline Computational & $\begin{array}{l}\text { Multiscale } \\
\text { model for vis- } \\
\text { coelasticity }\end{array}$ & $\begin{array}{l}\text { Generalized } \\
\text { Kelvin-Voigt } \\
\text { model in a } \\
\text { finite element } \\
\text { environment }\end{array}$ & $\begin{array}{l}\text { Numerical simu- } \\
\text { lations of relax- } \\
\text { ation of produc- } \\
\text { tion stresses in } \\
\text { glulam beam }\end{array}$ \\
\hline
\end{tabular}



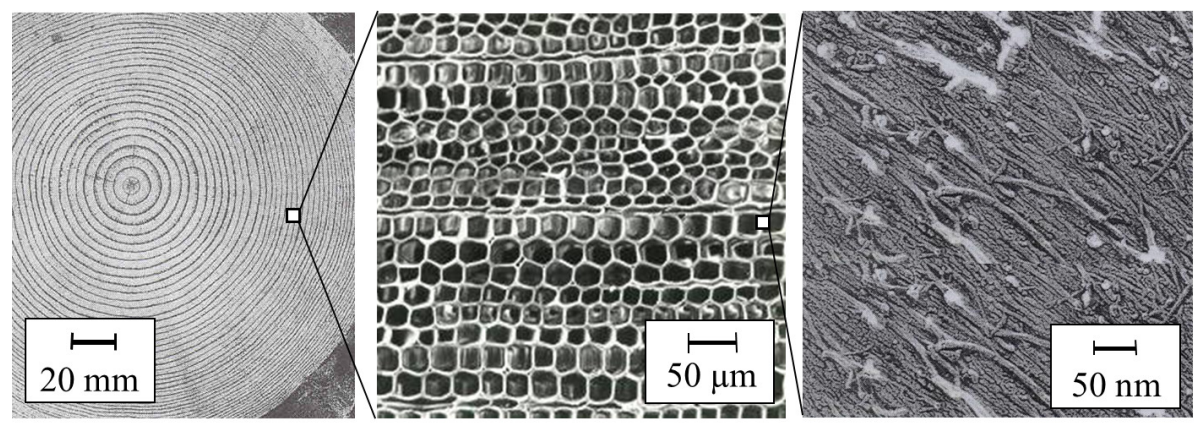

Figure 1: Hierarchical structure of wood: concentric growth rings (left), honeycomb structure of wood cells (middle), fiber composite structure of cell wall (right)

\section{Hierarchical structure of wood}

In order to provide the required basic knowledge for the subsequent (mechanical) explanations, we start with a very brief introduction to wood anatomy (see also Fig. 11 and Fengel et al. (1984); Wagenführ (2007)). Wood is composed of the macromolecules cellulose, hemicellulose, and lignin for the most part. Hemicelluloses and lignin build an amorphous matrix, in which cellulose fibers are embedded. Under wet conditions, also water is incorporated into this polymer network. Cellulose provides stiffness and strength to wood, show- ing mechanical characteristics closely approaching those of steel. Its fibers show a crystalline core and an amorphous sheeting at dimensions of typically several tens of nanometers in thickness. The resulting fiber-reinforced composite serves as the basic mate- rial for building a honeycomb-type cell structure. The cellulose fibers are inclined to the cell axis and wind in the cell wall in a helical fashion. The cells themselves show a hexagonal to rectangular cross-section with typical diameters of 20-80 $\mu \mathrm{m}$. Different cell dimensions and cell wall thicknesses in different growth regions during a year and, thus, different mass densities, finally result in the growth ring pattern visible to the naked eye. Altogether, this complex hierarchical structure causes pronounced anisotropy and complexity of the macroscopic material behavior. The mathematical description of the latter as well as further examinations in more detail wherever needed for the mechanical developments are described in the next sections.

\section{Modeling elastoplasticity}

\section{II.1 Microscale experimental investigations and multiscale modeling}

The complex microstructure, where different characteristic structural elements are superimposed to each other at consecutive length scales, brings about a highly diversified failure behavior at the macroscale. Depending on the loading state, brittle failure modes are observed as well as pronouncedly ductile ones, almost similar to the behavior of metals with a distinct yield plateau. Moreover, the variability of absolute strength values is enormous. Also for a particular failure mode, strength varies considerably across the wood species as well as across different mass densities and moisture contents of the material as the main influencing characteristics. Variations in morphological properties across all length scales, from the nano to the macrolevel, provide the material with different resistance to mechanical loading.

Many of the macroscopically observed failure modes can be traced back to one and the same microscale failure mechanism. The macroscopic variability is then only imposed by the structural features and their combined action at higher length scales. Multiscale models provide suitable tools 
to link microscale and macroscale failure criteria. Moreover, the representation of the hierarchical structure in these models enables to assess the influence of particular morphological characteristics and to come up with sample-specific estimates of wood strength properties. Quantification of the macroscopic variability based on the known variability of microstructural features could be achieved in the framework of a stochastic finite element approach (Liu et al. 1986). The multiscale model would then provide estimates for material properties at integration point level for randomly chosen microstructural characteristics, capturing the prescribed variability of these characteristics. The main influencing microstructural parameters are - in addition to mass density and moisture content - the microfibril angle and the shape and arrangement of the wood cells. The latter particularly affect the properties in the transverse directions perpendicular to the stem direction. At the structural scale, the effect of knots and growth irregularities, such as fiber deviations, are superimposed to the material variability and mainly control the mechanical behavior and its variability at this scale.

In the following, the formulation, evaluation, and validation of a multiscale failure model is demonstrated, taking shear failure of lignin as example of a microscale failure mechanism. The relevance of this failure mode is underlined by wide experimental evidence of separated cellulose fibers at loading states approaching the strength of wood (Hepworth and Vincent, 1998; Zimmermann et al., 1994). The failure of lignin can be suitably described by a von Mises-criterion (Bader et al. 2011b). The stress state in lignin is assessed in terms of quadratic strain averages over this phase, which provide measures of the mean absolute level of the stresses in this phase (Suquet. 1987; Bader et al. 2011a). These averages can be obtained by derivation of the macroscopic potential energy with respect to the elastic moduli of this phase (Dormieux et al. 2002). The required relation between macroscopic material properties, controlling together with the macroscopic loading (in terms of macroscopic stresses or strains) the macroscopic potential energy, and the lignin moduli is established by means of multiscale homogenization (Bader et al. . 2011b).

Continuum micromechanics and the unit cell method are employed, as well as lamination theory at the growth ring scale. These techniques allow estimation of effective material properties of micro-heterogeneous materials from the properties, the content, and the arrangement of their microscaled constituents (Zaoui, 2002; Suquet, 1997). Thereby, the properties of an equivalent homogeneous material are identified which shows the same behavior when subjected to particular loading states as the actual micro-heterogeneous one. Four homogenization steps are formulated for softwood (cf. Fig. 2): The first homogenization step concerns the mixture of hemicelluloses and lignin at a length scale of some nanometers in an amorphous material denoted as polymer network. If also water is incorporated in this matrix in moist states, a poro-mechanical framework is applied (see Bader et al. (2011a) for details). In the second homogenization step, inclined fiber-like aggregates with a core of crystalline cellulose and a sheeting of amorphous cellulose, exhibiting typical diameters of $20-100 \mathrm{~nm}$, are embedded in this polymer network. At a length scale of about one hundred microns, the material softwood is defined, built up by wood cells forming a honeycomb structure of hollow tubes oriented in the stem direction. The stiffness of the honeycomb is estimated in a third homogenization step by the unit cell method, which is chosen in order to suitably resolve bending and out-of-plane shear deformations at transverse loading (Hofstetter et al. 2007). Finally, the succession of dense and, thus, stiff latewood layers and lighter and, thus, softer earlywood layers is considered in the framework of lamination theory.

The formulation of the multiscale model as well as the derivation of microscale strain estimates are described in Bader et al. (2011a) in detail. Finally, insertion of the strain estimates into the local failure criterion (von Mises) for lignin yields the sought estimates for elastic limit stresses (Hofstetter et al. 2008; Bader et al. 2011b) at given loading states. These stresses refer to ultimate strength in case of brittle failure and to elastic limit stresses in case of ductile failure 


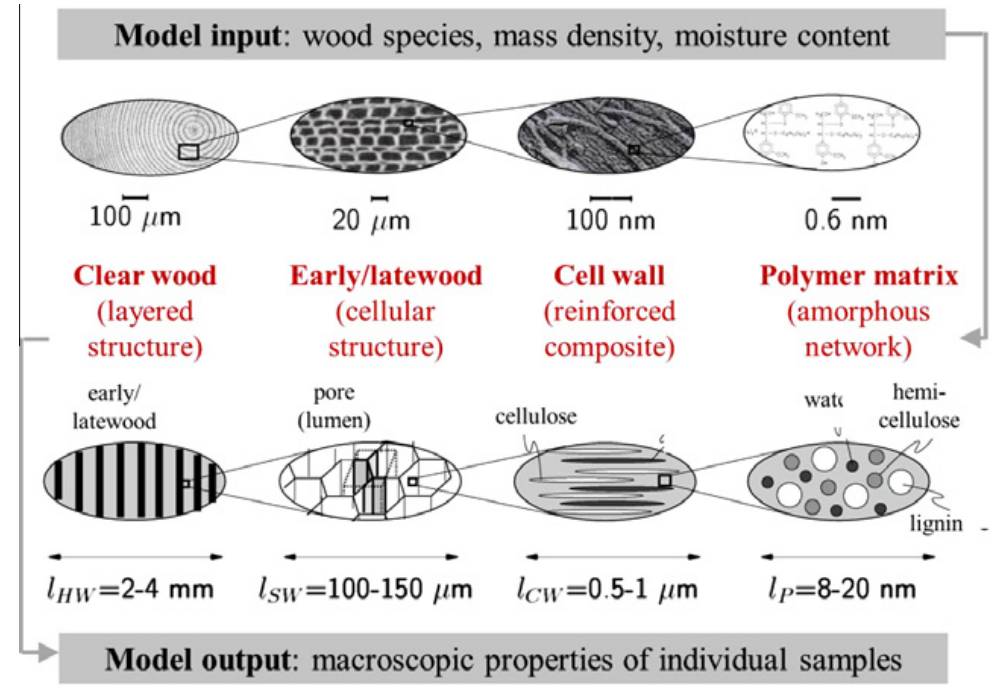

Figure 2: Hierarchical structure of wood and its representation in the micromechanics model

(Bader et al. 2011b). On the whole, the multiscale model provides predictions of tissue-specific (orthotropic) macroscopic elastic constants and elastic limit states of wood from tissue-specific chemical composition, mass density, and moisture content, based on the universal elastic properties of the nanoscaled constituents (crystalline and amorphous) cellulose, hemicellulose and lignin (see (Hofstetter et al. , 2007, 2008) for the values). Due to the lack of data from direct strength tests on lignin, its shear strength has been back-calculated from selected macroscopic test results related to shear-dominated loading states of the lignin matrix (Bader et al. 2011b).

\section{II.2 Biaxial mechanical tests and their application to experimental validation}

The performance of the multiscale model is assessed by com- paring model estimates for elastic limit states of wood with corresponding experimental data in a one-to-one fashion. Results of biaxial tests are particularly suited for this purpose, since they reflect at least the two-dimensional load-carrying characteristics of the (orthotropic) material wood and thus, are more challenging to be represented by a model than results of uniaxial tests.

A comprehensive series of biaxial tests on clear spruce wood samples was performed by one of the authors in the 1990's (Eberhardsteiner. 1995). These tests aimed at the determination of the stiffness and strength of spruce wood samples loaded in the $L R$-plane (i.e. in a plane parallel to the fibers and perpendicular to the growth rings) under different inclinations to the fiber direction $\varphi$. Different biaxiality ratios $\kappa$, which denote the ratio of the compressive or tensile stresses in the principal loading directions of the test specimens, were investigated. The self-developed testing device consists of a biaxial, servo-hydraulic strength testing unit for load application and a speckle-interferometer for spatial, contact-free deformation measurement. The spatial measurement allows also control of homogeneity of the deformation state in the measurement field of the cruciform test specimen sized $140 \times 140 \mathrm{~mm}^{2}$ (Fig. 3). The tests were carried out in a displacement-controlled manner, whereby the individual displacements of the 12 load application points were pre-determined by means of finite element simulations in order to achieve loading states free of shear stresses. Biaxial stress curves for zero loading angle are shown in Fig. $3(\mathrm{~b})$ in 


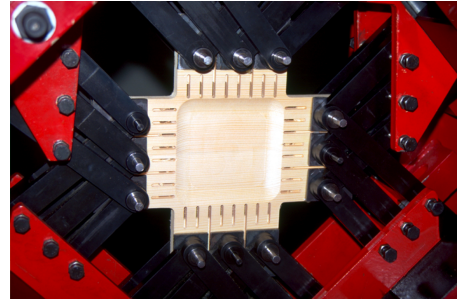

(a) Mounted test specimen

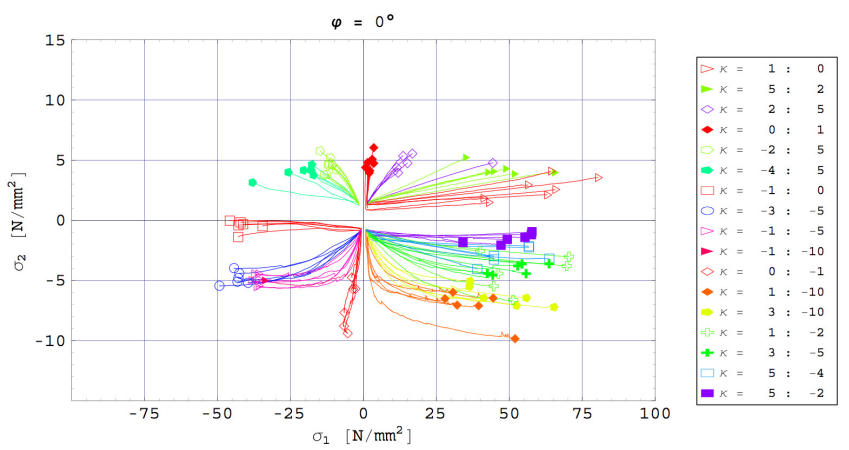

(b) Results for loading angle $\varphi=0^{\circ}$

Figure 3: Biaxial tests on spruce wood

an exemplary manner. A full listing of the results as well as a more comprehensive description of the tests are found in Eberhardsteiner (2002).

As for the model validation, results of tests with fiber inclinations of $\varphi=0^{\circ}$ and of $\varphi=30^{\circ}$, respectively, are evaluated. The failure surfaces predicted for the mean density of all samples (solid lines in Fig. 4) and for their maximum and minimum density, respectively, (dashed lines in Fig. 4) enclose most of the experimental strength data (marked by crosses in Fig. 4). At predominant tensile loading parallel to the grain (L-direction), a remarkable number of experimental points lies outside the predicted failure surface related to lignin failure. These points refer to situations where lignin failure does not directly cause overall composite material failure because of still intact cellulose fibrils, so that the (predicted) elastic limit falls below the (measured) ultimate strength. Otherwise, model estimates agree well with experimental results for ultimate stresses in case of brittle failure (tension- dominated loading states) and for yield limits in case of ductile failure (compression-dominated loading states) (Bader et al. 2011b), see Fig. 4 . This expresses the fundamental role of lignin as strength-determining component in wood and confirms the suitability of the developed multiscale model.
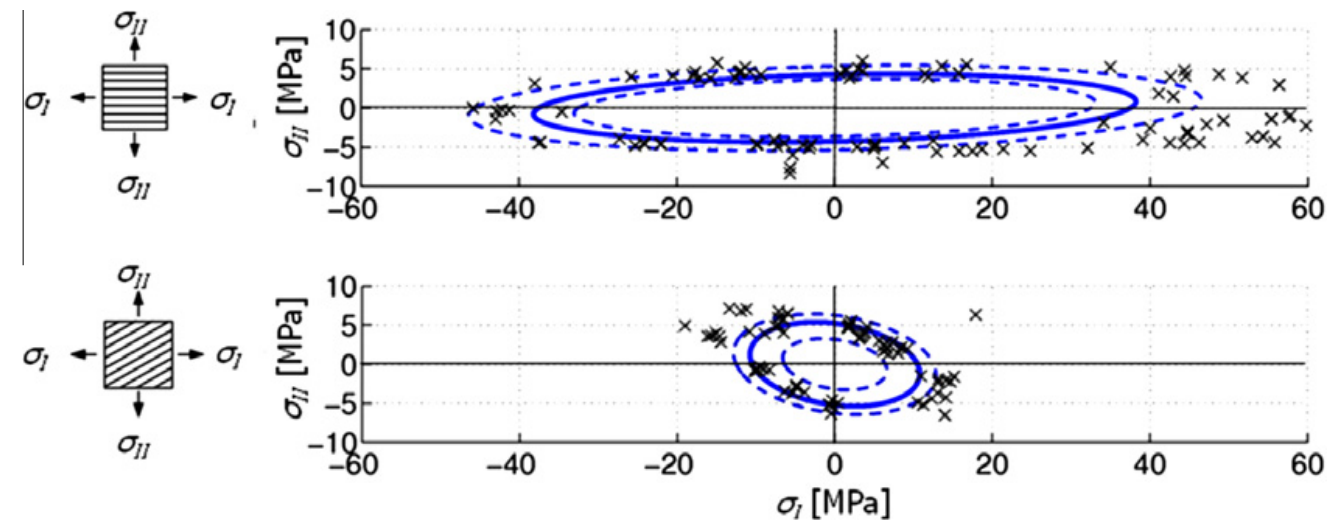

Figure 4: Model-predicted failure surfaces (solid line - mean density, dashed lines - max/min density of all samples) and experimental results (crosses) of biaxial tests on spruce wood 


\section{II.3 Macroscopic models for elasticity and ductile failure}

Considering engineering applications of numerical structural analyses by means of the finite element (FE) method, macroscopic material models are essential (Schmidt and Kaliske, 2009 Resch and Kaliske, 2010: Saft and Kaliske, 2011). The engineering parameters defining these models, such as elastic constants and failure properties, can be identified for sample-specific settings of mass density and moisture content from predictions of the presented multiscale model for various loading states. Alternatively, experimental results as shown in SubSection II.2 can be used for this purpose. Due to the growth ring structure, a cylindrical anisotropic material formulation is most suitable for structural investigations. Locally - i.e. at integration point level in a FE framework - the material properties are defined in the common orthotropic frame spanned by the longitudinal, the radial, and the tangential direction. The latter description also underlies the described multiscale model. If the location of the pith is unknown, a Cartesian coordinate system with identical material properties in radial and tangential direction can be chosen alternatively.

A few models have been developed to describe the nonlinear material behavior of wood numerically. A ground-breaking plasticity formulation for anisotropic materials was published by Tsai and $\mathrm{Wu}$ (1971). The Tsai-Wu-criterion has been used and enhanced in several works and also shown to suitably describe experimentally ob- served failure states (e.g. Eberhardsteiner (2002)).

In order to base the formulation of the criterion on physically meaningful parameters and to allow accurate fitting to experimental and/or micromechanical model predictions, an alternative plasticity formulation was developed (Schmidt, 2009: Schmidt and Kaliske, 2009) which will be summarized subsequently. The use of several yield surfaces more- over enables a more accurate representation of the various macroscopic failure modes of the material and, particularly, the pronouncedly different hardening/softening behavior related to each of these modes.

\section{II.3.1 Multi-surface plasticity}

Although a strain based formulation might be more appropriate for numerical reasons (MackenzieHelnwein et al. 2005), a stress based presentation is chosen here since it is more reasonable from an engineering point of view. Besides, stress and strain based models can easily be converted into each other (Moss, 1984).

The model is based on a multi-surface plasticity formulation with anisotropic yield surfaces (Mackenzie-Helnwein et al., 2005). Here, the yield condition

$$
f(\sigma) \leq 0
$$

is a function of stress $\sigma$ and can be described by known material parameters, for example strengths or elastic limits. The formulation of $f$ defines the transition between the elastic and inelastic area. The region of plasticity is formulated by using seven yield surfaces modeled by the following failure modes:

1. tension in radial direction,

2. pressure in radial direction,

3. tension in tangential direction,

4. pressure in tangential direction,

5. tension in longitudinal direction, 
6. pressure in longitudinal direction,

7. shear failure.

A maximum of four failure modes can be activated simultaneously, due to the exclusion of pressure and tension failure in one direction at the same time. Every flow condition $m$ is defined in form of

$$
f_{m}=\mathbf{a}_{m}: \sigma+\sigma: \mathfrak{b}_{m}: \sigma+q_{m}-1 \leq 0 .
$$

The tensors of strength $\mathbf{a}_{m}$ and $b_{m}$ for failure mode $m$ contain information on material strengths and elastic limits in relation to failure mode $m$. They are given for every yield surface in detail in Schmidt (2009). The parameter $q_{m}$ is a function of inner variables in order to take the hardening and softening behavior into account as described below.

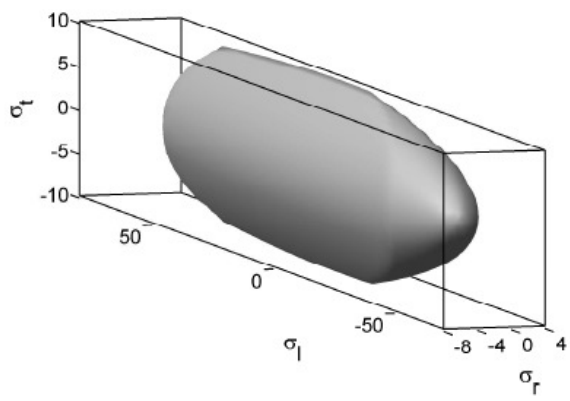

Figure 5: Yield surfaces of material point

Figure 5 shows the yield surfaces of a material point. For a defined stress state inside the body of yield surfaces, elastic behavior exists. For the multi-surface plasticity model, the associated flow rule

$$
\dot{\varepsilon}^{p}=\gamma \frac{\partial f(\sigma, \mathbf{q})}{\partial \sigma}
$$

is used, where $\mathbf{q}=\left\{q_{m}\right\}$. The whole formulation of the material model is developed and linearized consistently for small deformations and large displacements and is implemented in an in-house FE-code.

\section{II.3.2 Softening/hardening rules}

The material response of wood is ductile under compression. For the elastoplastic nonlinear behavior under compression, three yield conditions are considered for

1. pressure in radial direction,

2. pressure in tangential direction,

3. pressure in longitudinal direction

according to Eq. 22. The scalar parameter $q_{m}$ is a function of the inner variable $\alpha_{m}$. For the three kinds of failure under pressure, it is calculated by

$$
q_{m}=\left(1-\kappa_{m}\right) \cdot\left[1-\exp \left(-\eta_{m} \cdot \alpha_{m}\right)\right]
$$


before densification of the material and by

$$
q_{m}=\left(1-\kappa_{m}\right) \cdot\left[1-\exp \left(-\eta_{m} \cdot \alpha_{m}\right)\right]-\zeta_{m} \frac{\left(\alpha_{m}-\alpha_{m, d}\right)^{2}}{\alpha_{m, \max }-\alpha_{m}}
$$

in the phase of densification. The scalar parameters $\alpha_{m, d}$ and $\alpha_{m, \max }$ define begin and end of the densification process. The parameters $\kappa_{m}, \eta_{m}$ and $\zeta_{m}$ affect the shape of the hardening/softening function. Figure 6 shows the parameter $q_{m}$ and the resulting stress-strain behavior. No micromechanical investigations were performed so far in relation to the material behavior beyond the elastic limit. Thus, the parameters of the hardening/softening functions have to be determined from experimental results (e.g. Eberhardsteiner (2002)). According extensions of the micromechanical model constitute future research efforts.
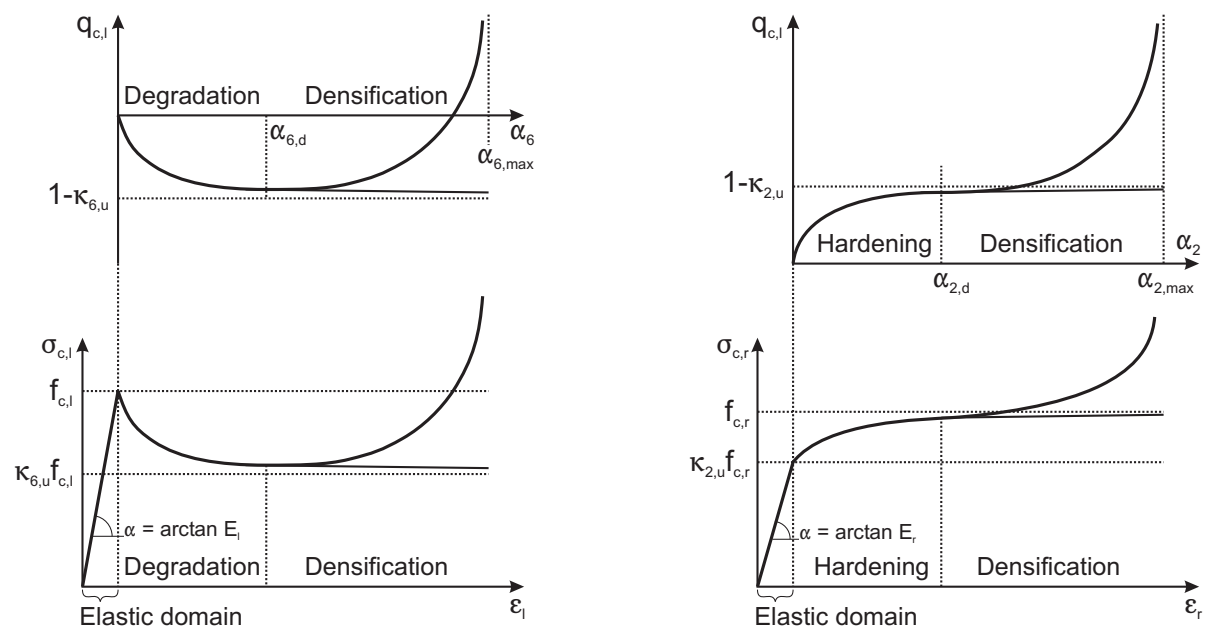

Figure 6: Development of the parameter $q_{m}$ and the stress-strain behavior at compression

\section{II.4 Structural simulations of dowel-type connections and corresponding tests}

As an example for the application of the multi-surface model in timber engineering, the deformation and failure properties of a dowel-type connection have been studied. Aside from numerical simulations, also tests were performed in order to verify the numerically predicted behavior.

Different experimental configurations with different specimen dimensions and material properties were tested. The standard configuration, which was also analyzed numerically, is shown in Fig. 7 .

The considered timber element is slotted at both ends to implement the steel sheets (cf. Fig. 7(a) . Object of the investigation is the single dowel on the left-hand side in Fig. 7(b), which is also depicted in the photo of the experimental device. On the right-hand side, the support by three dowels can be seen. The analyzed dowel has a diameter of $d=12 \mathrm{~mm}$, the support dowels a diameter of $d=16 \mathrm{~mm}$. All dowels are made of steel S235. The steel sheet has a thickness of $t=8 \mathrm{~mm}$ and is made of S355. The density $\rho$ of the applied Norway Spruce is varying for the different specimen between 360 and $513 \mathrm{~kg} / \mathrm{m}^{3}$. The grain course is equal to the direction of loading (x-direction in Fig. $7(\mathrm{~b})$. Displacement-controlled pulling tests $(v=1 \mathrm{~mm} / \mathrm{s})$ were performed, some with partial unloading and reloading.

As a first numerical study of the presented connection, the model is kept simple in order to reduce the numerical effort and provide results quite fast. Since the focus of the investigation lies 


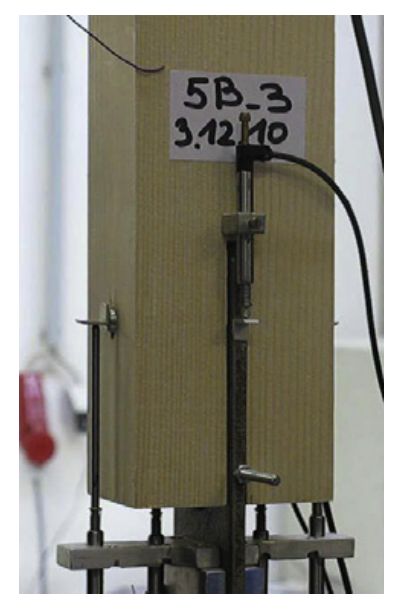

(a) Photo of test device

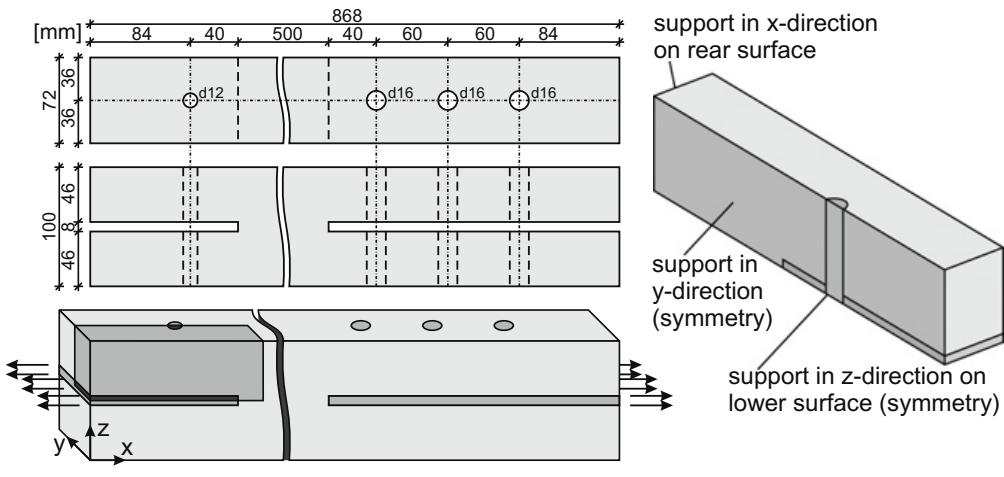

(b) Geometry and dimensions of model for FE analysis

Figure 7: Analyzed dowel-type connection

on the single dowel on the left-hand side (Fig. $7(\mathrm{~b}))$, the support is not modeled. Instead, only the left part of the connection until a length of $224 \mathrm{~mm}$, i.e. further $100 \mathrm{~mm}$ from the end of the sheet, is simulated. In addition, to reduce the numerical effort, the symmetry of the structure is utilized. The joint is symmetric in a horizontal and a vertical plane, each in the middle. The reduced geometry is shown in Fig. $7(\mathrm{~b})$. The boundary conditions are illustrated in Fig. $7(\mathrm{~b})$ as well. The support by the three dowels is modeled by fixed boundary conditions in x-direction.

In Fig. 8, the applied FE mesh is illustrated. In different shades of gray, the utilized threedimensional continuum elements and the related material models can be seen. The whole model is composed of 8-node displacement elements with linear shape functions, except for the core of the dowel where so-called "wedges" (6-nodes elements) are applied. Alternatively, 20-nodes elements with quadratic shape functions could be used Resch and Kaliske (2010). However, the higher accuracy would lead to an increasing numerical effort.

Dowel and steel sheet are modeled by an isotropic material formulation based on the von Mises yield criterion (without hardening). The wooden part is modeled to a great extent by an anisotropic linear elasticity formulation. Local areas of high stresses with possible plastic deformations can be found in the contact zones of the dowel. Therefore, the multi-surface plasticity according to Resch and Kaliske (2010) is utilized (Fig. 8).

Experimental observations show that failure due to transversal tension often occurs in the vertical symmetry plane. Although the presented plasticity model is suitable to capture tensile and shear failure in principle, cohesive elements are applied here since they allow a discrete crack modeling. Besides, a continuum based failure description based on damage or plasticity could yield strong mesh dependencies due to localization which can easily be avoided by using cohesive elements. Therefore, cohesive elements, also referred to as interface elements, with a related material model according to Schmidt and Kaliske (2007) and Schmidt (2009) are implemented in this possible failure plane (Fig. 8). Parallel, half a dowel diameter in distance, a second potential failure plane can be found. There, failure due to shearing of the front wood can be observed frequently. This shear failure is as well captured by a plane of interface elements (Fig. 8). If potential failure planes are not known or can not be assumed realistically, an adaptive meshing procedure may be used (Geissler et al. 2010).

In addition, contact surfaces are defined between the timber and the steel parts. The contact 


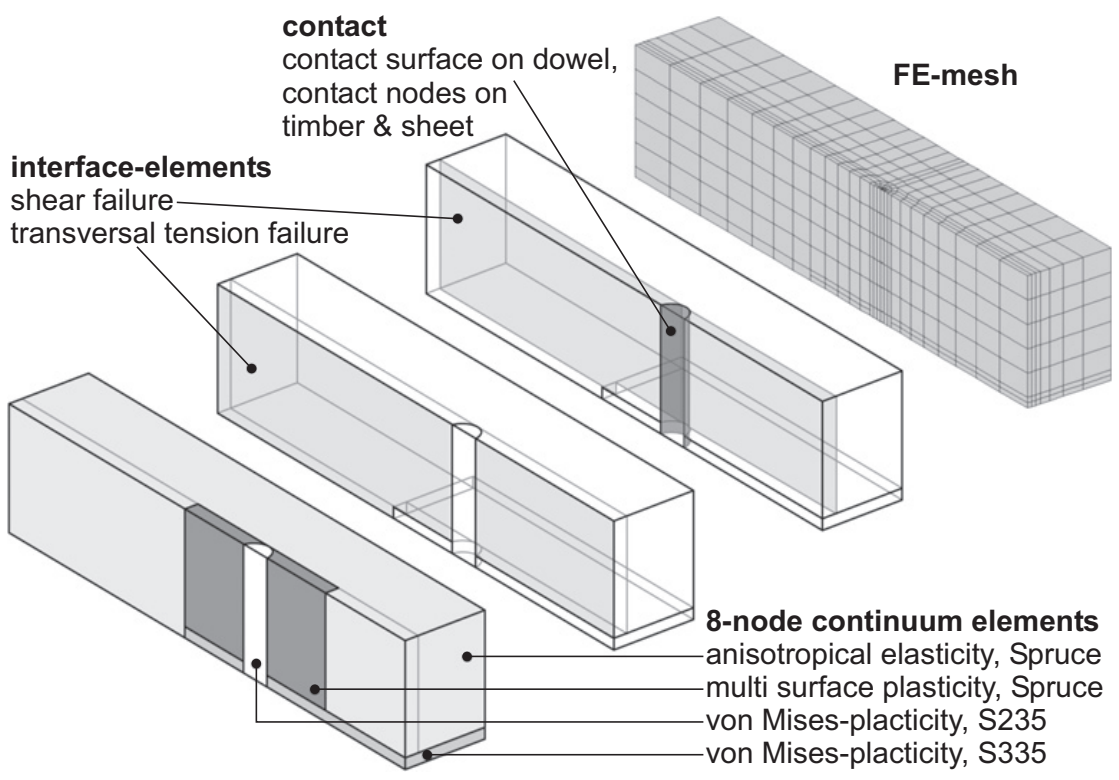

Figure 8: FE model: continuum elements, cohesive elements, and contact surfaces

formulation uses Beziér-areas (see Schmidt (2009) for details) and assumes frictionless behavior.

As for the wooden parts, the density of the investigated samples, which predominantly determines all mechanical parameters, varied between 360 and $513 \mathrm{~kg} / \mathrm{m}^{3}$. Based on experimental studies and micromechanical model estimates for the correlation of the density and parameters like elasticity moduli and material strengths (amongst others in Kollmann (1982); Eberhardsteiner (2002)) the material parameters given in Table 2 are chosen for the simulation. The material parameters for the modeling of the dowel (S235) and the steel sheet (S355) are chosen according to DIN EN 10025 and given in Table 2 as well.

Table 2: Material properties of timber and steel used in the simulations

\begin{tabular}{lll}
$\mathrm{E}_{\mathrm{l}}=10000 \mathrm{~N} / \mathrm{mm}^{2}$ & $\mathrm{G}_{\mathrm{lr}}=600 \mathrm{~N} / \mathrm{mm}^{2}$ & ${ }_{\mathrm{or}}=0.45$ \\
$\mathrm{E}_{\mathrm{r}}=400 \mathrm{~N} / \mathrm{mm}^{2}$ & $\mathrm{G}_{\mathrm{lt}}=600 \mathrm{~N} / \mathrm{mm}^{2}$ & ${ }_{\mathrm{lt}}=0.45$ \\
$\mathrm{E}_{\mathrm{t}}=400 \mathrm{~N} / \mathrm{mm}^{2}$ & $\mathrm{G}_{\mathrm{rt}}=100 \mathrm{~N} / \mathrm{mm}^{2}$ & ${ }_{\mathrm{rt}}=0.24$ \\
$\mathrm{f}_{\mathrm{c}, \mathrm{l}}=-40 \mathrm{~N} / \mathrm{mm}^{2}$ & $\mathrm{f}_{\mathrm{v}, \mathrm{lr}}=6 \mathrm{~N} / \mathrm{mm}^{2}$ & $\mathrm{G}_{\mathrm{lr}}=1 \mathrm{Nmm}$ \\
$\mathrm{f}_{\mathrm{c}, \mathrm{r}}=-6 \mathrm{~N} / \mathrm{mm}^{2}$ & $\mathrm{f}_{\mathrm{v}, \mathrm{t}}=6 \mathrm{~N} / \mathrm{mm}^{2}$ & $\mathrm{G}_{\mathrm{lt}}=1 \mathrm{Nmm}$ \\
$\mathrm{f}_{\mathrm{c}, \mathrm{t}}=-6 \mathrm{~N} / \mathrm{mm}^{2}$ & $\mathrm{ft}_{\mathrm{t}, \mathrm{r}}=3 \mathrm{~N} / \mathrm{mm}^{2}$ & $\mathrm{G}_{\mathrm{r}}=0.2 \mathrm{Nmm}$ \\
& $\mathrm{f}_{\mathrm{t}, \mathrm{t}}=3 \mathrm{~N} / \mathrm{mm}^{2}$ & $\mathrm{G}_{\mathrm{t}}=0.2 \mathrm{Nmm}$ \\
$\mathrm{E}=210000 \mathrm{~N} / \mathrm{mm}^{2}$ & $\mathrm{G}=81000 \mathrm{~N} / \mathrm{mm}^{2}$ & ${ }^{\circ}=0.3$ \\
$\mathrm{f}_{\mathrm{S} 235}=235 \mathrm{~N} / \mathrm{mm}^{2}$ & $\mathrm{f}_{\mathrm{S} 355}=355 \mathrm{~N} / \mathrm{mm}^{2}$ & \\
\hline
\end{tabular}

In Fig. 9. load-displacement relationships of a displacement- controlled simulation are depicted. Thereby, the displacement curve of the steel sheet gives insight into the global behavior of the structure. In addition, further curves of different points in the wooden part are illustrated to evaluate local effects. 

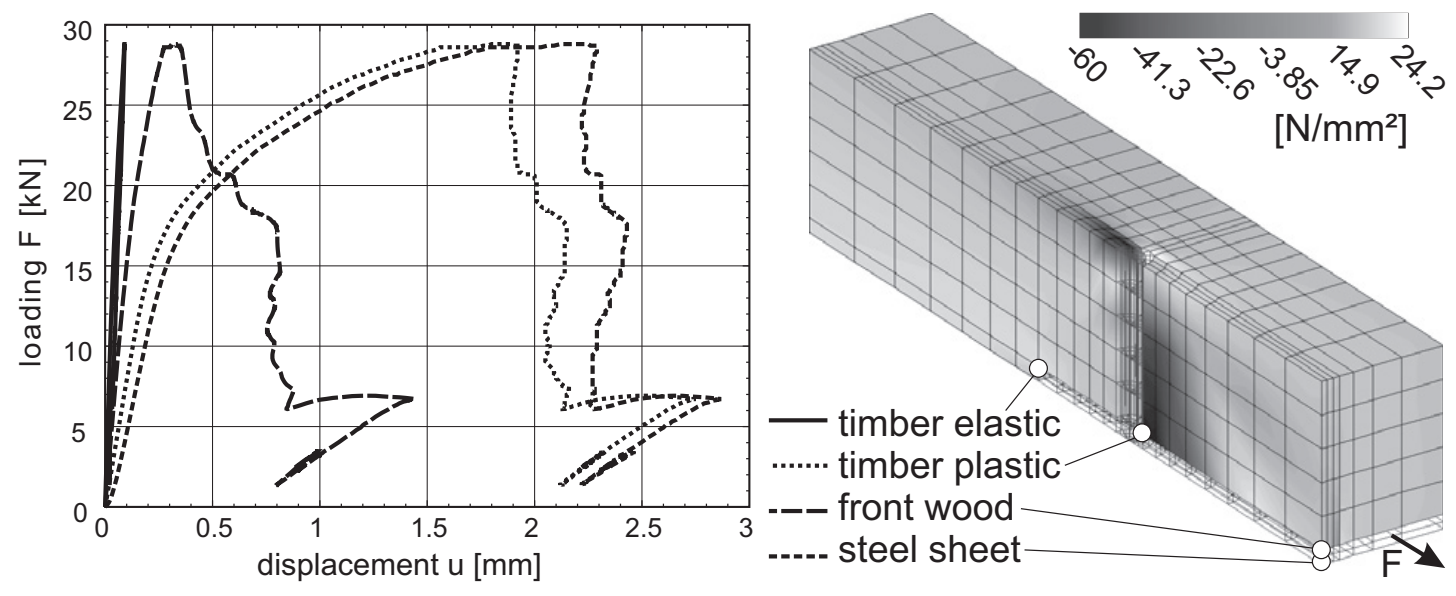

Figure 9: Load-displacement dependency obtained by simulation

The material behavior of the timber in the "rear" area according to Fig. 9 can be described as being almost linear elastic. Due to the displacement-control, the structure is unloaded in the post damaged regime after reaching the ultimate load. The path of unloading of the elastic curve is then almost equal to the loading path. The deformation computed on the lower part of the dowel (denoted as plastic in the diagram) is larger than the deformation of the front wood. High compressive stresses lead to a local plasticization and large strains which decrease to the top of the front wood. The ultimate load is calculated to yield approx. $30 \mathrm{kN}$. Shear failure leads to global collapse. This behavior of rupture is accompanied by local failure due to plasticization.

In Fig. 10, the plasticized areas and the degree of plasticization are illustrated. In the contact zone, the wood plasticizes as well as the dowel and the steel sheet. Fig. 10 shows also the load-displacement dependency of the sheet obtained by the simulation with partial unloading and reloading in comparison to the experimental observations. The loading process is given in Fig. 10 as well. In the experiment, every load step has been held about $30 \mathrm{~s}$. Since no time-dependent effects are considered in the material formulation applied in the simulation, the path for unloading and reloading is identical. In reality, the typical loops observable in the experimental curve in Fig. 10 will develop.

The ultimate load is predicted quite well by the simulation. Remaining differences might be explained by the uncertainty of the material properties. The input parameters were defined only by the given densities. Therefore, the applied material parameters represent only a rough estimation.

The displacement of the experiments is larger than in the simulation (related to the predicted force). Additionally, the stiffness at the beginning of the load-displacement characteristic is much larger in the simulation than in the experiment. One possible reason for this discrepancy could be the reduced model in which the rear part of the test specimen is not captured (Fig. 7(b)). This simplification leads to generally smaller displacements. A reason for the difference in stiffness can be found in the contact definition: Friction between timber and steel is neglected. Especially the roughness of the boreholes has a large influence on local effects. Considering the experiments, the very low stiffness in the early stage clearly indicates contact finding and included effects like slippage, adhesion and friction which are not captured in the simulation. These conclusions might be confirmed by the fact, that the stiffness of unloading and reloading of the experiments 


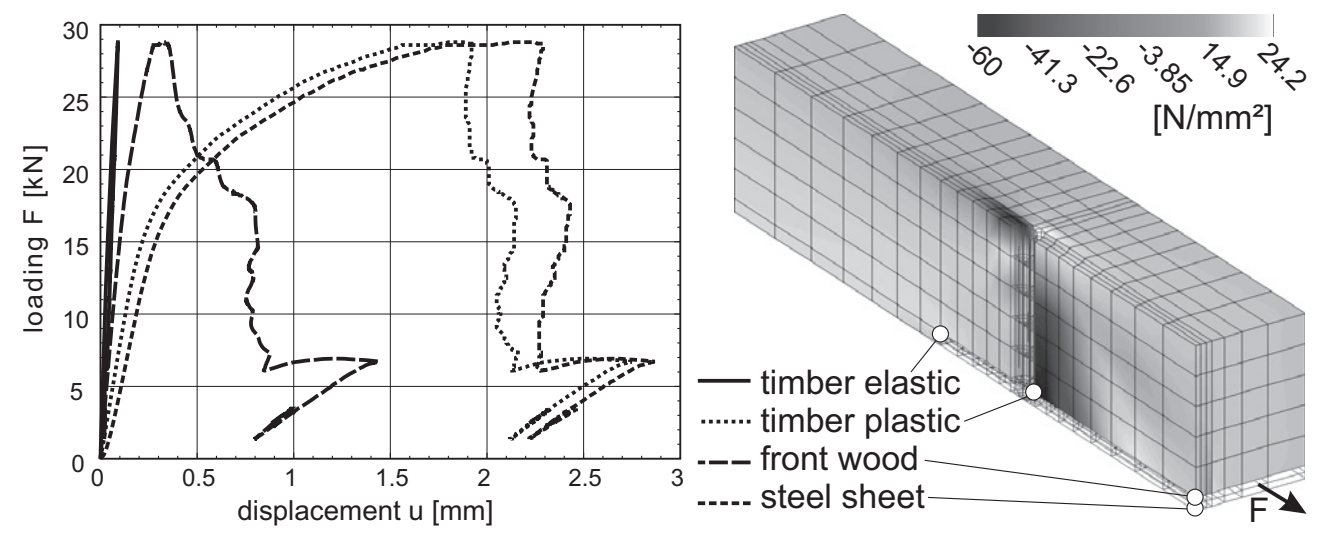

Figure 10: Stress in timber in fiber direction in $\mathrm{N} / \mathrm{mm}^{2}$ and comparison between simulation results and corresponding experimental data and plasticized areas

is equal to the stiffness of the simulation in general. The applied contact formulation is able to capture contact features like adhesion and friction. As a main problem, the realistic parameter identification remains. Therefore, these effects have been neglected in this example for simplicity. Using the experimental data, the model could be expanded to capture these features in the next step. Besides, the applied plasticity formulation is only valid for small strains and large deformations. In the contact zone of the dowel, large strains occur. However, the results show that the models already enable a good approximation of reality. Considering friction and improving the models by a large strain formulation would of course lead even to a better quality of the simulation of the load bearing behavior of timber structures. Clarification of the origin of the deviations between simulations and experiments and according improvement of the numerical model are subject of ongoing and future research efforts, both experimental and numerical.

\section{Modeling VISCOELASTICITY}

Wood shows distinct time-dependent deformations, which are generally ascribed to the viscoelastic behavior of the wood polymers hemicellulose and lignin. The intrinsic amorphous constitution of these polymers together with their organization in a heterogeneous framework bring about a pronouncedly anisotropic time-dependent behavior of wood at the macroscale. Various theoretical models have been formulated to explain the time-dependent macroscopic properties of wood in relation to its anatomical features (Schniewind, 1968: Boyd, 1982). Herein, we test this hypothesis about the origin of wood viscoelasticity, striving for a better understanding of the mechanisms involved in time-dependent behavior of wood. We particularly investigate the contribution of cellulose. Thereon, we develop a multiscale model which represents the entire hierarchical structure of wood and allows to link microscale viscoelastic deformations to corresponding macroscopic effects. Further experiments at the macroscopic scale add on information about the interaction with the mechanosorptive response, i.e. the increased time-dependent deformations upon changes of the moisture content. These experimental investigations together with the micromechanical efforts were finally used to develop macroscopic models for structural simulations. 


\section{III.1 Microscale experimental investigations and multiscale modeling}

In order to evaluate the real contribution of crystalline cellulose to the macroscopic wood behavior, X-Ray Diffraction (XRD) experiments were performed on poplar specimens using a specific bending device (Fig. 11(a)) mounted on a goniometer head (Fig. 11(b)). The macroscopic strains have been measured using strain gages on the upper (compressive) and lower (tensile) side, respectively $\varepsilon^{-}$and $\varepsilon^{+}$. The mechanical responses of the cellulose crystals in tension and in compression, respectively, are analyzed within the same specimen during a single experiment.
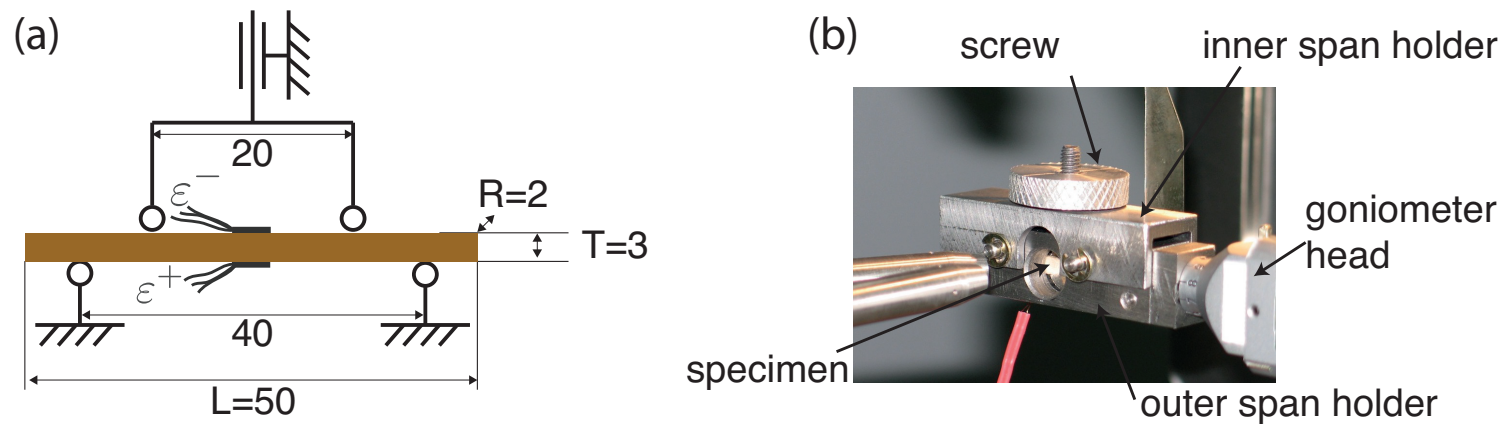

Figure 11: (a) Schematic view of the four-point bending device and specimen dimensions (all dimensions in mm). (b) Photography of four-point bending device specially designed for the X-ray goniometer head

With the developed method (Montero et al. 2011b), the strain of crystalline cellulose is obtained with sufficient accuracy. The relationship between cellulose crystal strain and macroscopic strain is close to linear, with a proportionality ratio of approx. $\Gamma=0.75$ (Fig. 12). No significant difference is observed between the two sides of the specimen, even up to strain levels close to the elastic limit (approx. $0.3 \%$ ).

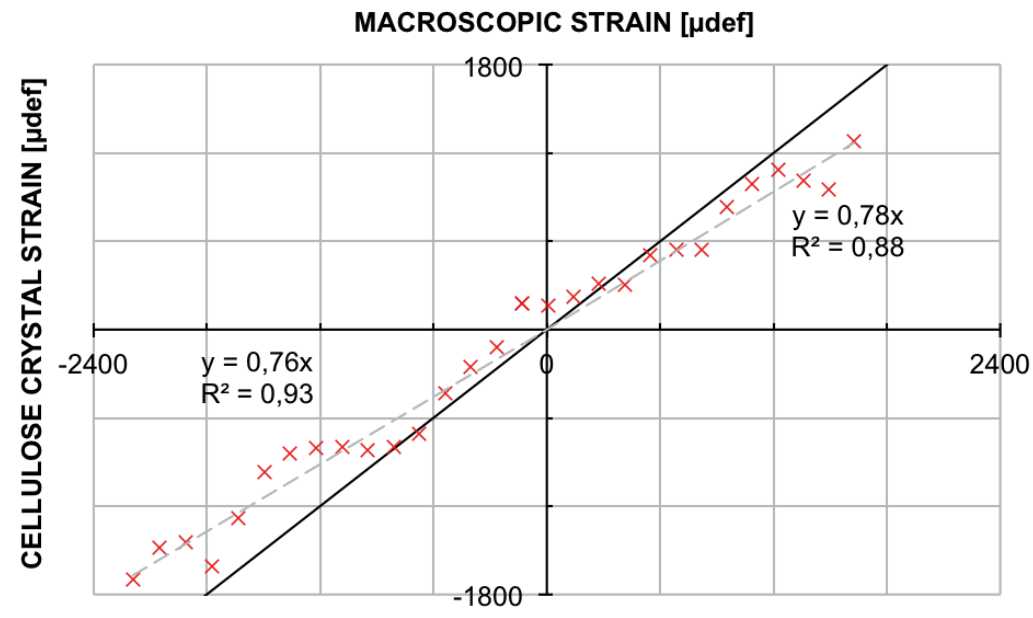

Figure 12: Relationship between cellulose crystal strain and wood macroscopic strain (applied at approx. $0.2 \%$ ) $\times$ experimental results, - - regression line of experimental results, - 1:1 line

The results obtained in this experiment are in accordance with most of those obtained in tension at low strain level (Suzuki, 1968, 1969, Nakai et al. 2005, 2006). A value of the strain 
ratio $\Gamma$ below one results partly, but not completely, from a geometrical effect of the microfibril angle (MFA). The inclination of the microfibrils towards the longitudinal direction evokes a contribution of amorphous regions situated in series with the cellulosic cell wall fibers. Expressing the longitudinal strain in terms of its amorphous and cell-wall contributions reads as

$$
\varepsilon=\varepsilon_{L}^{W}\left(\varepsilon^{C}, \mu\right)+\varepsilon^{A}=\frac{\varepsilon^{C}}{\cos \mu^{2}+v_{L T}^{W} \sin \mu^{2}}+\varepsilon^{A}=\varepsilon^{C} \cdot f\left(\mu, v_{L T}^{W}\right)+\varepsilon^{A}
$$

where the cell-wall contribution $\varepsilon^{W}$ is expressed as a function of the cellulose crystal strain $\varepsilon^{C}$, the MFA $\mu$, and the cell-wall Poisson's ratio $\nu_{L T}^{W}$. $\varepsilon^{A}$ is an additive contribution that does not involve the crystalline regions. Setting $\Gamma=0.75, \mu=15^{\circ}$ and $v_{L T}^{W}=0.8$ in Eq. (6), we can evaluate the ratio of $\varepsilon^{A} / \varepsilon$ as $12 \%$.

Various other mechanisms occurring at different scales within the material can be included in $\varepsilon^{A}$. They are detailed in Montero et al. (2011b).

Similar tests have been performed using the method designed under constant load in order to study the viscoelastic response. In the instantaneous state, identical results to the previous tests with controlled, constant strain have been obtained. After two days of creep without environment control, the strain ratio had decreased both in the tensile and in the compressive zone, indicating a smaller contribution of the cellulose crystal strain to the viscous deformations than to the elastic ones. The presence of amorphous cellulose zones in serial arrangement to crystalline zones can originate viscous deformations within the cell-wall network. Moreover, load transfer between the polymer matrix and the cellulose microfibrils can occur and appear as a decrease of the contribution of the crystalline cellulose. No fully quantitative results are available yet. Those time-dependent results are the subject of our future research.

Further support of a dominant contribution of the (amorphous) polymer matrix to timedependent deformations is provided by the observations that hemicellulose-deficient samples show less longitudinal creep (Fioravanti et al. 2006) and that the macroscopically detected longitudinal creep increases with larger microfibril angles of the samples (Lotfy et al., 1972).

Upscaling of viscoelastic properties can be accomplished by means of the correspondence principle (Mandel, 1966) (cf. Fig. 13). After a Laplace-Carson $(\mathcal{L C})$ transformation, the relaxation

\begin{tabular}{|c|c|c|}
\hline \multicolumn{2}{|c|}{$\begin{array}{c}\text { Viscoelastic } \\
\text { material behavior }\end{array}$} & $\begin{array}{c}\text { Elastic } \\
\text { material behavior }\end{array}$ \\
\hline Time domain & Laplace Carson domain & \\
\hline $\boldsymbol{\sigma}_{r}(t)=\int_{0}^{t} \mathrm{r}_{r}(t-\tau): \dot{\boldsymbol{\varepsilon}}_{r}(\tau) \mathrm{d} \tau, \quad \overrightarrow{L C}$ & $\boldsymbol{\sigma}_{r}^{*}(p)=\mathbb{r}_{r}^{*}(p): \boldsymbol{\varepsilon}_{r}^{*}(p)$ & $\boldsymbol{\sigma}_{r}=\mathbb{C}_{r}: \varepsilon_{r}$ \\
\hline & Homogeniz & tion \\
\hline$\Sigma(t)=\int_{0}^{\sigma} \mathbb{R}^{\text {hom }}(t-\tau): \dot{\mathbf{E}}(\tau) \mathrm{d} \tau<\mathcal{L C}^{-1}$ & $\Sigma^{*}(p)=\mathbb{R}^{\text {hom }, *}(p): \mathbf{E}^{*}(p)$ & $\boldsymbol{\Sigma}=\mathbb{C}^{\text {hom }}: \mathrm{E}$ \\
\hline
\end{tabular}

Figure 13: Strategy for upscaling of viscoelastic properties using correspondence principle: $\sigma_{r}, \varepsilon_{r}, r, r-$ stress, strain, relaxation tensor, and stiffness tensor of phase $r ; \Sigma, \mathbf{E}, \mathbb{R}^{\text {hom }}, \mathbb{C}^{\text {hom }}$ - respective macroscopic (homogenized) quantities; superscript ${ }^{*}-\mathcal{L C}$-transformed quantities 
and creep equations exhibit an identical structure as the constitutive equations for the elastic behavior (Gurtin and Sternberg, 1962). Then, the same multiscale model can be applied for upscaling of $\mathcal{L C}$-transformed viscoelastic properties as for upscaling of elastic properties (Eitelberger et al. 2011), cf. Fig. 2. A back-transformation of the homogenized properties finally yields the sought effective viscoelastic material characteristics in terms of effective relaxation moduli and creep compliances. Mechanosorptive effects in consequence of changes of moisture content during mechanical load are not considered in the developed model. Related material properties, which are essential for structural scale simulations, are derived from experiments on macroscopic samples as detailed in Section III.2. Also nonlinear effects, which might occur above the linear viscoelastic limit, are not implemented in the model yet. These issues are again subject to future extensions of the multiscale model.

It is assumed that the matrix polymers exhibit viscoelastic behavior at shear loading, while behaving purely elastically at volumetric loading. Potential additional viscoelastic deformations of the cellulose are disregarded, given the experimental indications of dominance of the matrix in a viscoelastic context. For polymers, the viscoelastic shear behavior can be typically described in terms of a power-law model (Plaseied and Fatemi, 2009: Eitelberger et al. 2011). This model consists of a linear spring connected in series with a nonlinear, parabolic dashpot, involving altogether two material parameters: a creep compliance and a creep exponent. Since no experimental data are available for the viscoelastic behavior of the matrix polymers, these two parameters were back-calculated for a joint hemicellulose-lignin-matrix from selected results of macroscopic creep tests, namely data for normal creep in longitudinal direction (Schniewind and Barrett, 1972) (cf. Fig. 14 , blue line).
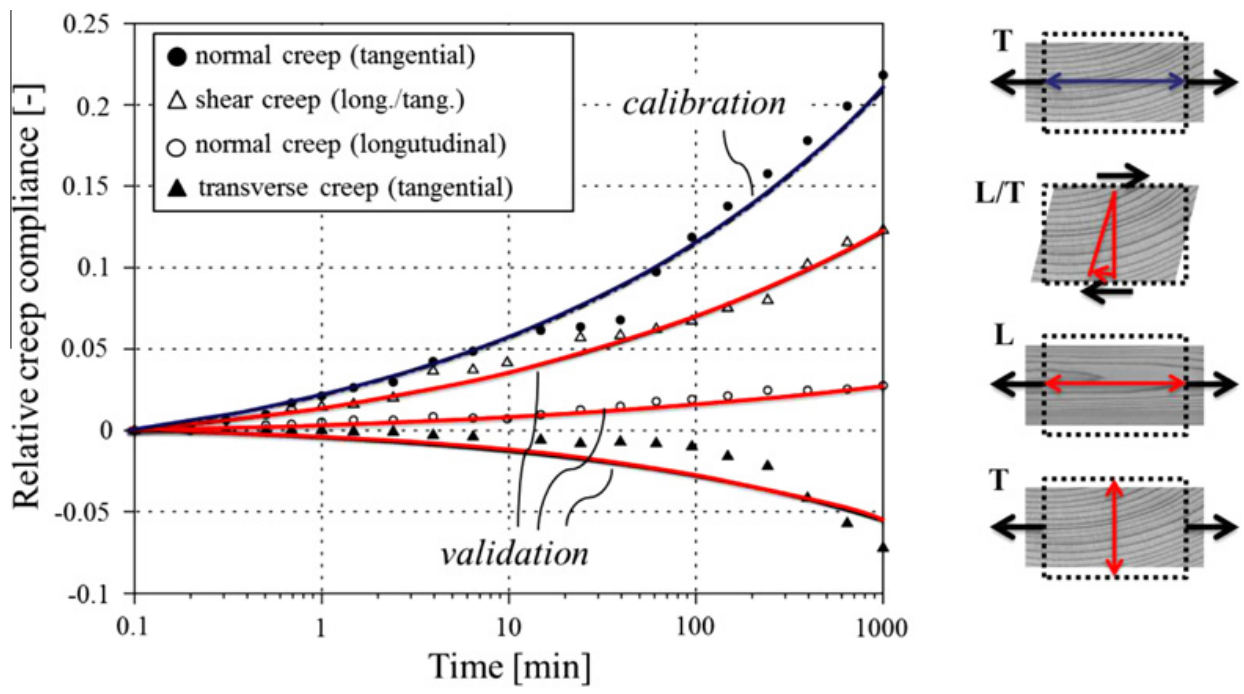

Figure 14: Comparison of model predictions for relative creep of wood samples with corresponding experimental results

Similarly to the model for elastic limits, the multiscale model for viscoelastic behavior of wood provides estimates for (orthotropic) compliances for given species, mass density, and moisture content at constant moisture content over time.

Further data reported in Schniewind and Barrett (1972) for creep at other loading modes were used for validation of the model by comparing model predictions with corresponding test data (cf. Fig. 14, red lines). The good agreement confirms the suitability of the model and of the basic assumption that viscoelastic behavior of the matrix polymers is the origin of macroscopic 
time-dependent deformations. Further experimental validation of the multiscale model across wider density ranges and across different species is still missing and planned for the future.

\section{III.2 Creep tests on macroscale specimens}

Because of its hygroscopicity, changes of the moisture content $w$ in a wood tissue affect its timedependent response (Nakano, 1999). In structural applications, wood is subjected to continuous changes of humidity. As mentioned before, the adsorption-desorption processes in addition to mechanical loading increase the observed deformations, which is generally referred to as mechanosorptive effect (Armstrong and Kingston, 1960: Armstrong and Christensen, 1961; Armstrong and Kingston, 1962: Grossman, 1976). This effect may accelerate the time-dependent response considerably. Various physical interpretations of this effect have been given, but up to now no consensus was reached (Boyd, 1982: Back et al., 1983; Mukudai, 1983; Bazant, 1985; Hoffmeyer and Davidson, 1989). First approaches to a quantitative description of the mechanosorptive effect (Ranta-Maunus, 1975) used hygroviscoelastic constants, equal to the compliance rate relative to moisture change, which were assumed to be different during the first adsorption under load (referred to as $a^{++}$-effect in wood science), desorption (referred to as $a^{-}$), and subsequent adsorption (referred to as $a^{+}$) (Fig 15(a)). Hunt (1984) has observed that these constants are straindependent values, and that a limit of the mechanosorptive response is reached asymptotically (Fig 15(b)). A practical consequence of that observation is to assume an equivalent contribution of adsorption and desorption to mechanosorptive creep. It is still under discussion if there is a
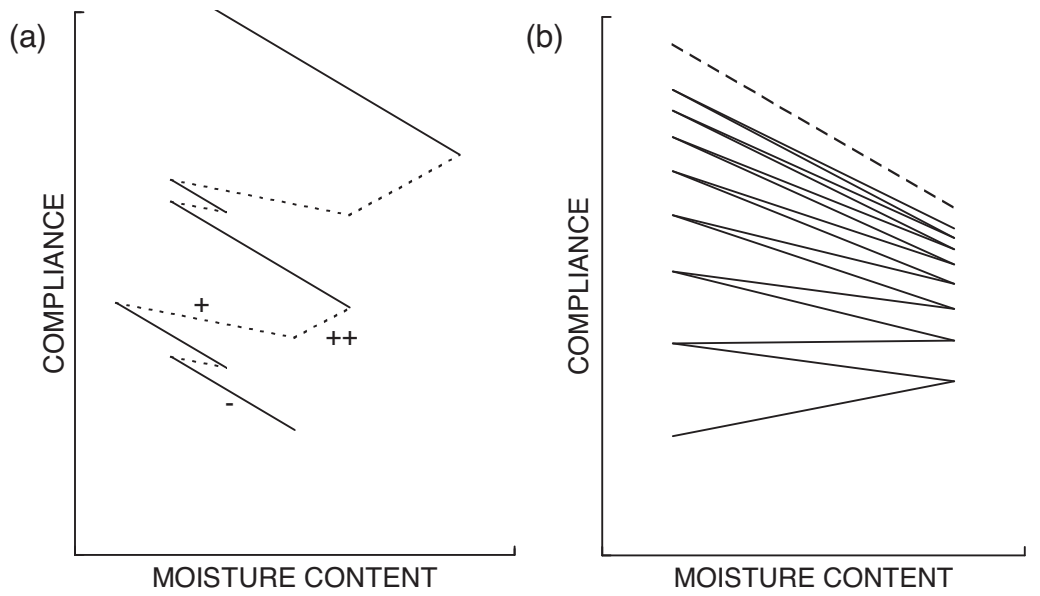

Figure 15: Hypothetical plots of compliance against moisture content (a) with strain-independent hygroviscoelastic constants, i.e. with constant values of $a^{++}, a^{+}$and $a^{-}$(humidifying -, dehumidifying - -) (from Hunt (1984)) and (b) with strain-dependency of the hygroviscoelastic constants, decreasing towards a creep limit (from Hunt (1989))

difference of the mechanosorptive response during first adsorption and later adsorption circles (the $a^{++}$-effect). In order to clarify this question and to derive data for later numerical simulations at the structural scale, bending tests on two matched spruce samples loaded in longitudinal direction were started. These two samples were subjected to the same hygroscopic history, but loaded at different humidity (Montero $e t$ al. . 2011a). After a preliminary acclimatizing phase to release internal stresses, the first set of specimens was loaded dry ( $w \simeq 11 \%)$ so that it experienced the ${ }^{++}$-situation during the following humidity increase (up to $w \simeq 19 \%$ ). The second set of 
specimens was then loaded in wet state $(w \simeq 19 \%)$, and its viscoelastic creep was observed. Both samples were then subjected to repeated cycling of the moisture content (between $w \simeq 19 \%$ and $w \simeq 11 \%$ ) (Fig. 16.(a)).

The compliance $J=\Delta \varepsilon / \sigma$ was estimated and observed against elapsed time (Fig. 16(c)), where the cross-sectional dimensions used for the stress calculation were corrected for changes upon moisture adsorption and desorption.

(a)

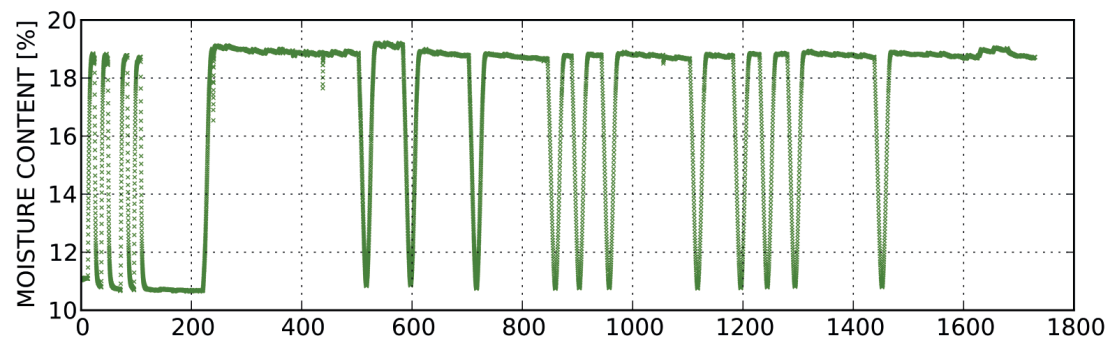

(b)

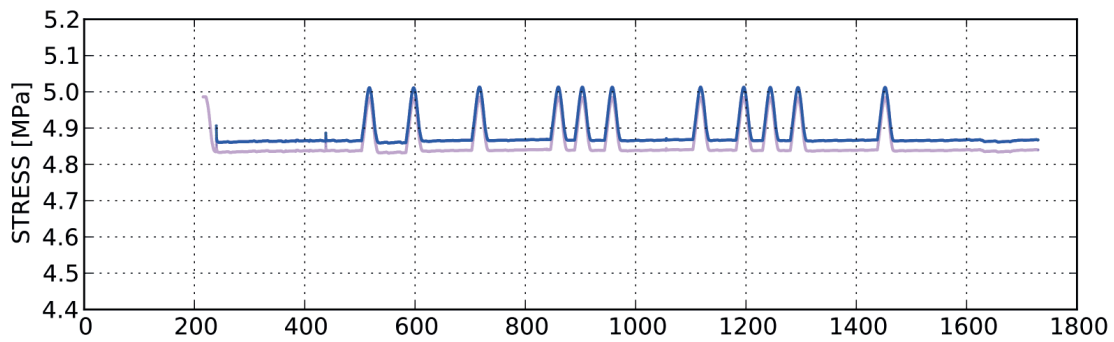

(c)

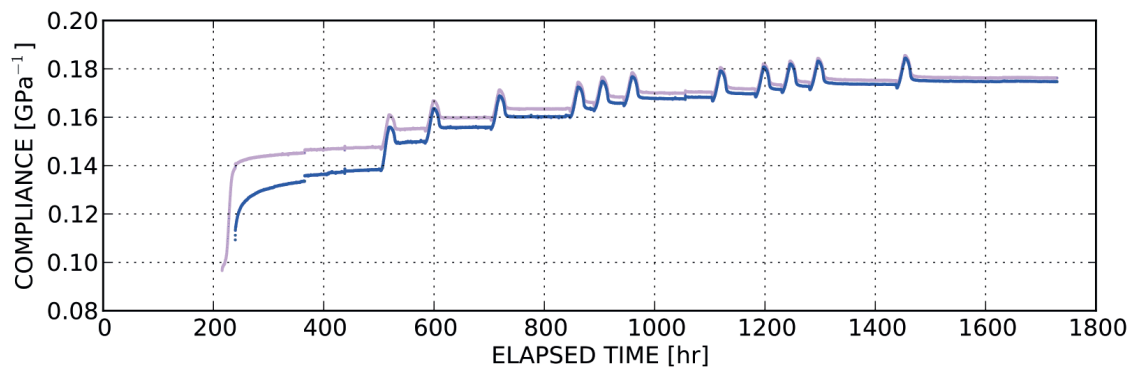

Figure 16: Time evolution of adapted data: (a) moisture content calculated from mean strain of the specimens (experiment at $T=23{ }^{\circ} \mathrm{C}$ ) (b) nominal stress $\sigma(c)$ compliance J (mauve line ... dry-loaded set, blue line ... wet-loaded set)

The compliance increase of the dry-loaded set during the first wetting leads to a higher levels than the wet-loaded set, subjected to viscoelastic creep at high humidity only. Even accounting for the small difference of loading time, this observation proves that the ${ }^{++}$-effect does involve mechanosorption and is not the mere expression of a higher creep rate in the wet state. However, after several humidity cycles, the response of both sets becomes almost identical (Fig. 17). This suggests that no special kind of mechanosorption has been induced during the first wetting under load, which clearly demonstrate that the concept of ${ }^{++}$-effect is non-relevant for wood. These conclusion relies strongly on the matching of the specimens, and a specific method of selection was designed to reduce sufficiently the consequences of wood variability (Montero et al. 2011a).

The evolution of timber deflection over time and hygrothermal environment is important in order to predict structural serviceability. In Fig. 18, the observed evolution of the compliance during the creep test is represented. After a period of creep at constant high moisture content 


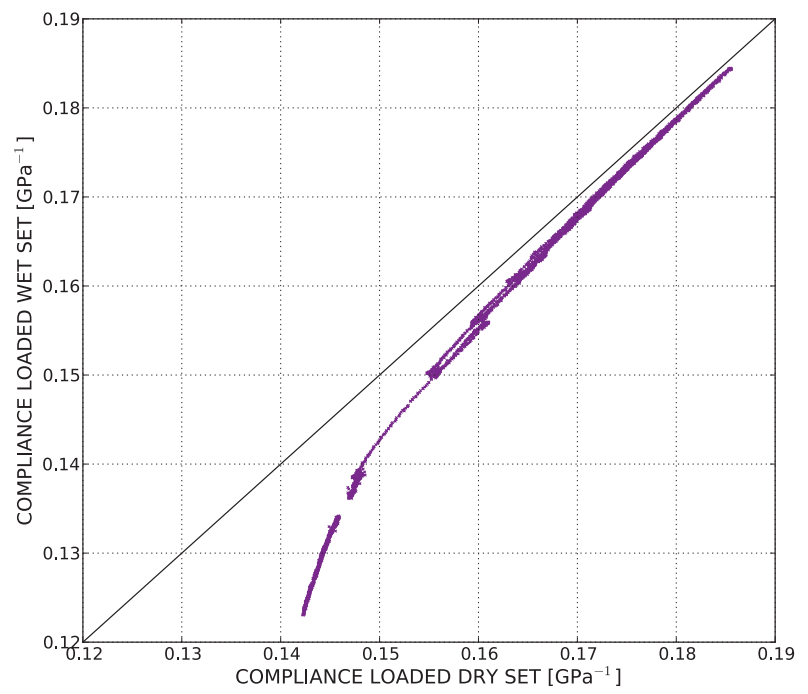

Figure 17: Compliance of wet-loaded set against that of dry-loaded set

$(w \simeq 26 \%$, a first desorption-adsorption cycle has induced a marked reduction of the slope as well as a compliance increment, which confirms that mechanosorption and creep are coupled phenomena (as discussed in Hanhijärvi and Hunt (1998)). The extrapolation of the wet creep by a sigmoid curve is based on a parabolic model fitted to the observed data. It allows to interpret the wet creep following the humidity cycle as the anticipation of the response that would have been observed in constant wet condition, according to a log-time shift. In addition, the humidity cycle has induced an additional portion of mechanosorptive strain. After further humidity cycles, the compliance rate vanishes. The positive difference between the compliance finally reached and the long-term viscoelastic prediction $\left(\Delta J=0.037 \mathrm{GPa}^{-1}\right)$ can be interpreted as a true mechanosorptive increment, independent from creep. In Fig. 18, the extrapolation of the wet creep response to 50 years based on a constant rate $d J / d \log t$ (leading to $J_{50 y}=0.231 \mathrm{GPa}^{-1}$ ) is also shown for comparison to the prediction by the parabolic model $\left(J_{50 y}=0.204 \mathrm{GPa}^{-1}\right)$.

\section{III.3 Macroscopic models for viscoelasticity}

As for structural applications, macroscopic rheological models can be fitted to the micromechanical model predictions for viscoelastic creep and the experimental results for mechanosorptive creep. For properties related to the longitudinal direction, i.e. for $E_{L}, G_{T L}, G_{L R}, v_{L R}$, and $v_{R T}$, a fractional Zener model (cf. Fig. 19(a)) is suitable for that, while for properties related to the transverse direction, i.e. for $E_{R}, E_{T}, G_{R T}$, and $v_{R T}$, a power-law model (cf. Fig. 19(b)) might be most appropriate.

These models are based on parabolic dashpots, which are defined by creep laws relating strain to time under constant stress. Combinations of such dashpots with springs have been used to describe linear creep of various materials, and were approved for wood creep in different loading directions by several authors (under restricted time windows and loading conditions).

However, parabolic models can hardly be used in numerical codes to simulate other tests than constant stress tests. A convenient formulation for that purpose is a generalized Kelvin-Voigt 

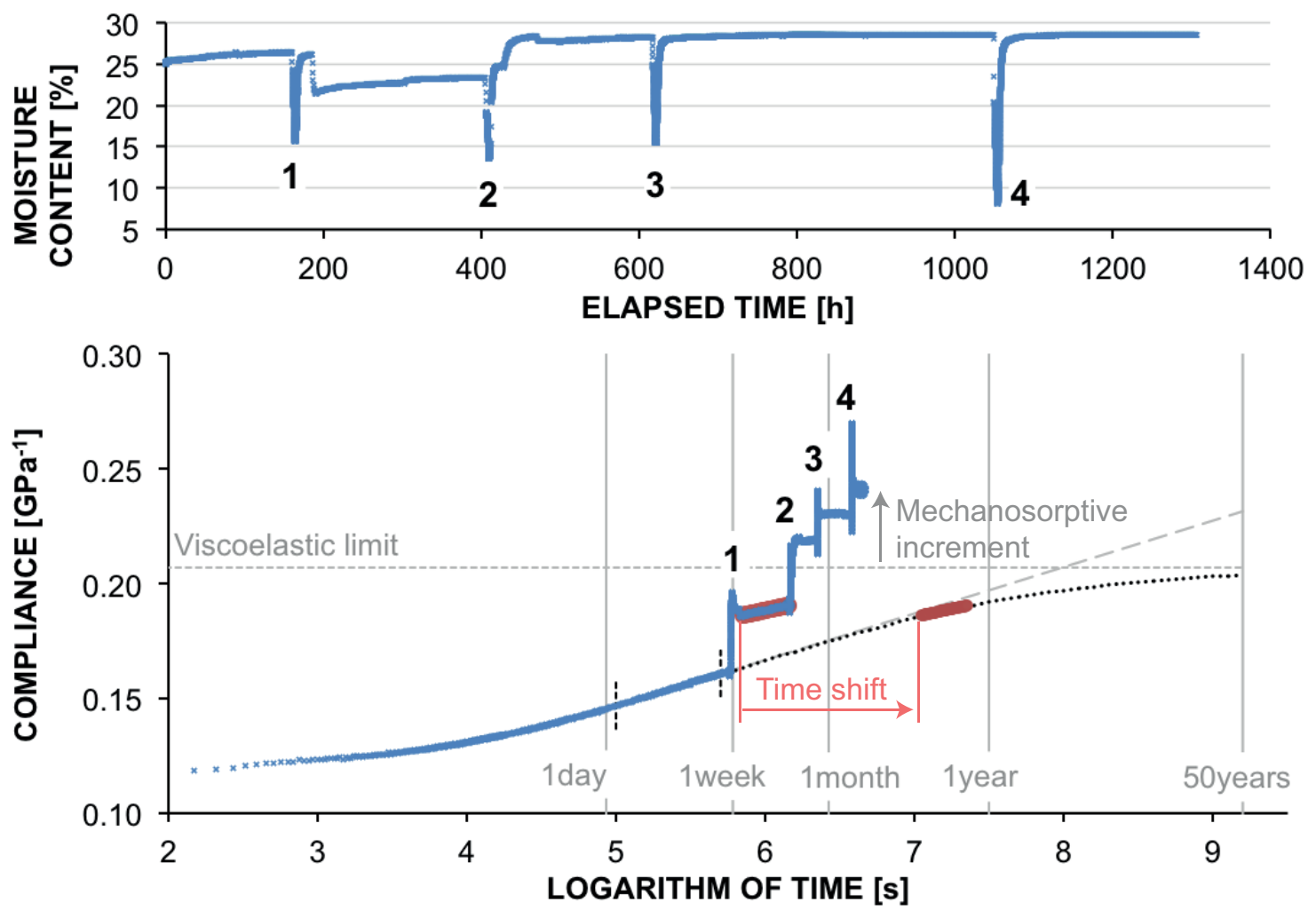

Figure 18: Evolution of compliance against logarithm of time (down) in humid environment ( $w \simeq 26 \%$ ) punctuated by four moisture content cycles to dry states (up)

model (Fig. 19(c)). Its application to the radial behavior of wet wood, being equal to a parabolic Zener model, is shown in Bardet and Gril (2002). Another application, namely to the investigation of production stresses in glulam beams, follows next.

\section{III.4 Structural simulation of stress relaxation in a glulam beam}

As an example of the application of the model for time- and moisture-dependent behavior of wood, the stress relaxation in a glued-laminated timber ('glulam') beam during fabrication is investigated. For this, a model for a multi-layered beam is developed, using a one-dimensional formulation for each layer and considering only variability along the thickness coordinate (Fig. 20 . The formulation for the time-dependent behavior of wood in different directions is based on a generalized Kelvin-Voigt model (Fig. 20). The behavior can be formulated using a discrete scheme over the time step $\Delta t$ :

$$
\Delta \varepsilon=P+Q \Delta \sigma
$$

or

$$
\Delta \sigma=B+C \Delta \varepsilon
$$

where $Q$ is the instantaneous stiffness, and $P$ expresses the previous hygromechanical history. These parameters are derived from the chosen generalized Kelvin-Voigt material model. Details on a discrete scheme using a GKV model for the hygromechanical behavior can be found in Colmar 


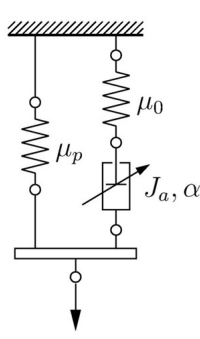

(a)

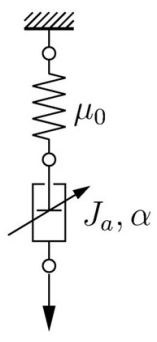

(b)

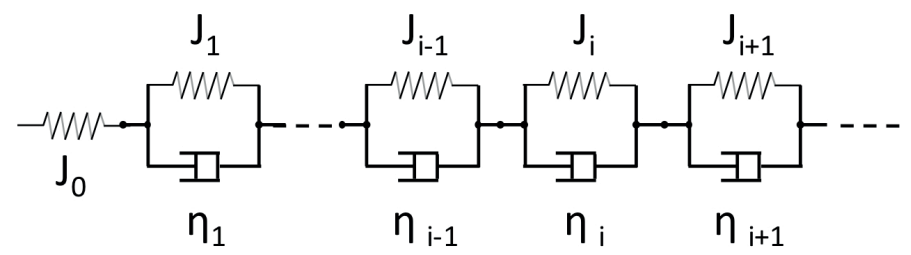

(c)

Figure 19: Rheological models for description of macroscopic viscoelastic behavior: (a) fractional Zener model, (b) power-law model, (c) generalized Kelvin-Voigt model

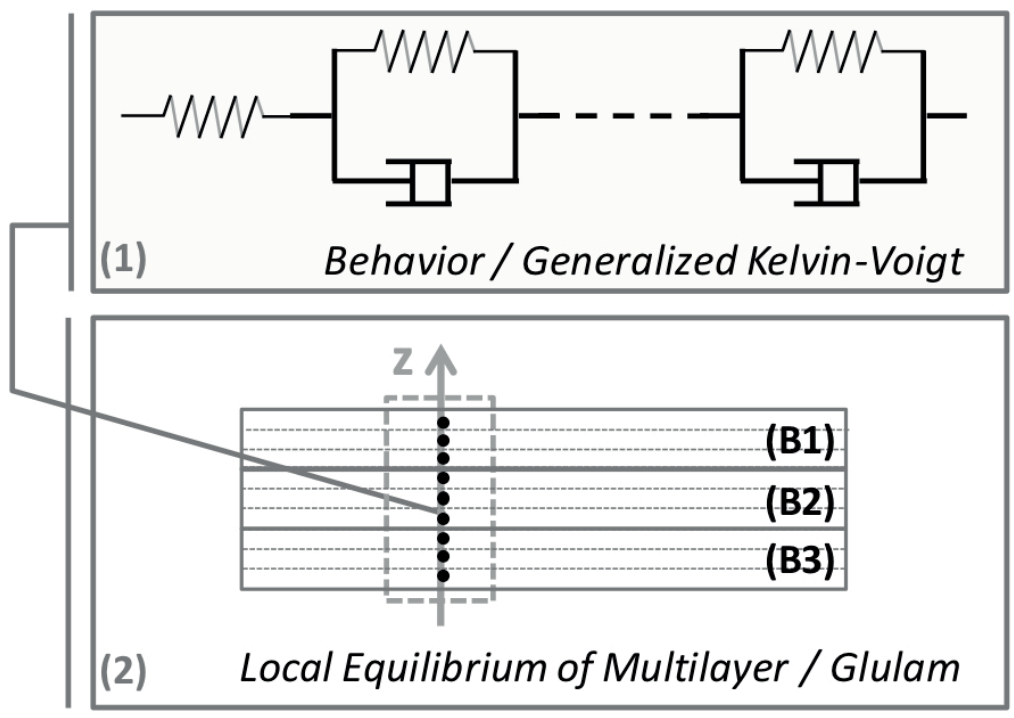

Figure 20: Behavior and structural levels of the numerical code

(2011), stating full expressions for $P$ and $Q . B$ and $C$ are then obtained by inversion, $C=Q^{-1}$ and $\bar{B}=-C P$. The kinematics is based on the conservation of plane sections:

$$
\Delta \varepsilon=\Delta e+z \Delta \chi,
$$

where $\Delta e$ is the mean membrane deformation, $\Delta \chi$ the flexion deformation, and $z$ the position in the thickness. Integration through thickness yields the following link at each $\Delta t$ of deformations $\Delta e$ and $\Delta \chi$ to increments of external normal load $\Delta N$ and moment load $\Delta M$

$$
\left[\begin{array}{cc}
\sum h_{k} C_{k} & \sum h_{k} z_{k} C_{k} \\
\sum h_{k} z_{k} C_{k} & \sum C_{k}\left(h_{k} z_{k}^{2}+\frac{h^{3}}{12}\right)
\end{array}\right]\left[\begin{array}{c}
\Delta e \\
\Delta \chi
\end{array}\right]+\left[\begin{array}{c}
\sum h_{k} B_{k} \\
\sum h_{k} z_{k} B_{k}
\end{array}\right]=\left[\begin{array}{c}
\Delta N \\
\Delta M
\end{array}\right]
$$

where $h_{k}$ is the height (thickness) of layer $k$.

As a numerical example, the fabrication of a 3-layered glulam beam is considered, in which the external lamellae (1 and 3) are made of high quality softwood (Eurocode class C40: longitudinal elastic modulus $E_{L}=14 \mathrm{GPa}$, mean density $\rho=500 \mathrm{~kg} / \mathrm{m}^{3}$ ), and the central lamella (2) is made of a low quality softwood (class C14: $E_{L}=7 \mathrm{GPa}, \rho=350 \mathrm{~kg} / \mathrm{m}^{3}$ ). The parameters of the generalized 
Kelvin-Voigt model (Fig. 19(c)) are fitted to creep results obtained on spruce by Montero (2010), taking additionally into account long-term effects predicted from humidity and specific modulus $\left(E_{L} / \rho\right)$ as proposed by Matar (2003). This specific procedure is detailed next.

Experimental work of Montero et al. (2011a) provided creep curves at two different relative humidity conditions for spruce (RH around 30\% and 90\%). Power law models (Fig. 19(b)) are defined by a delayed compliance reading as

$$
J(t)=J_{0}\left(1+(t / \tau)^{k}\right) .
$$

Couples of viscous parameters $(k, \tau)$ can be identified for both $\mathrm{RH}$ conditions by fitting power-laws to experimental results through the least square method.

In order to predict equivalent parameters for various $\mathrm{RH}$ and various wood qualities $\left(E_{L} / \rho\right)$, we used the approach proposed by Matar (2003). He found experimentally that relative creep of Ponderosa pine under constant load could be predicted (at a given time between one week and 50 years) by bilinear functions of material quality $\left(E_{L} / \rho\right)$ and environmental condition $\mathrm{RH}$. This approach was used to interpolate power-law creep functions at various RH in between the two (low and high $\mathrm{RH}$ ) creep curves obtained experimentally on spruce.

Finally we switch from creep power-laws to a complete material behavior formulation based on the generalized Kelvin-Voigt (GKV) model, which can be numerically handled in any mechanical loading. The principle is to identify a GKV model showing the same creep response as the power-law model. The one-dimensional GKV model used here consists of a series of the following elements:

- a spring of compliance $J_{0}$,

- a series of $(n-1)$ Kelvin elements of characteristic times equally spaced in log time scale from $\tau_{i}=1$ day to $10^{(n / 2)}$ days, associated with delayed compliances $J_{i}$, to describe long term time-dependent effects.

A good approximation of the power-law creep response is given by a GKV with a series of viscous compliances $J_{i}$ that fulfil

$$
\log \left(J_{i}\right)=A \log \left(\tau_{i}\right)+B,
$$

where $A$ and $B$ are two constant parameters, identified at a given humidity and for a fixed number of Kelvin units. The whole procedure gives all creep parameters at given $\mathrm{RH}$ condition $(60 \% \mathrm{RH}$ in our calculation) and for the various wood qualities of beams 1,2, and 3 . The length of the glulam beam was assumed to be $5 \mathrm{~m}$, its width $0.2 \mathrm{~m}$, and the height of each lamella $0.2 \mathrm{~m}$, so that the total height of the glulam beam is $0.6 \mathrm{~m}$.

Each beam is bent first (Fig. 21(a)), so that the strain profile is initially discontinuous across the thickness after gluing. Nevertheless, we assume that the subsequent variations respect the conservation of the new cross-section according to Eq. (9).

During the first step, each lamella is bent in a displacement controlled manner, resulting in moments $M_{1}, M_{2}$, and $M_{3}$ in the individual lamellae. The overall moment $M=M_{1}+M_{2}+M_{3}$ is maintained until the beams are glued. It is assumed that the gluing phase is instantaneous. After release of the overall bending moment, the beam recovers a part of its curvature instantaneously, followed by a gradual back-deformation due to the time-dependent response of wood (Fig. 21(b)). To simulate the strain-stress field along the thickness during these fabrication steps, each beam is divided into $k=20$ layers for calculation, and the behavior is homogeneous within a single layer.

Figure 22 shows the stress and strain profiles along the thickness of the whole glulam element, at three steps: initial (before gluing), elastic (after gluing and releasing the restraint) and delayed 

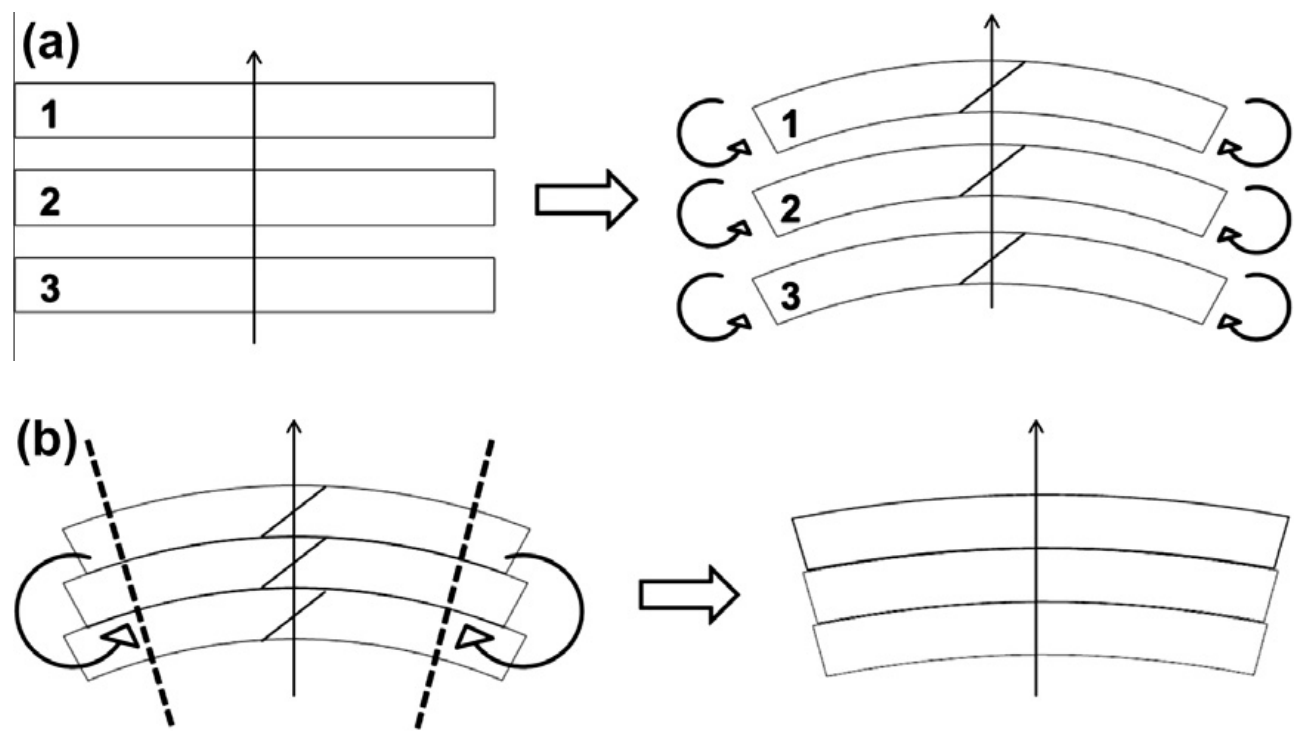

Figure 21: Fabrication steps (a) each individual beam is bent independently; (b) the bending moment is released and the assembled beam recovers

(after $\left.t=10^{4} \mathrm{~s}\right)$. It shows the stress history at given positions. In the outermost layers $(z=$ $\pm 300 \mathrm{~mm}$ ), about $1 / 4$ of the stress is released initially, and another one quarter after three years. At the interface $(z= \pm 100 \mathrm{~mm})$, the final release amounts to one third to one quarter of the initial stress.
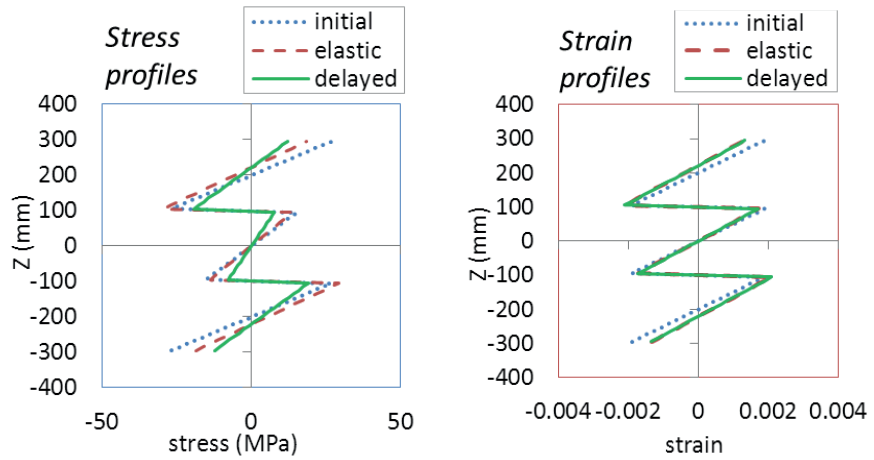

Figure 22: Stress (left) and strain (right) profiles at given time; initial: before gluing; elastic: after gluing and releasing the restraint; delayed: after 104 days

The current application dealt only with the simple case of a glulam beam kept unloaded after fabrication. The analysis of more complex fabrication and utilization steps, including drying under restraint or loading in changing humidity, could be simulated using appropriate input data. 


\section{SUMMARY AND CONCLUSIONS}

In this paper, a holistic approach to the mechanical characterization and modeling of wood is presented. It relies on combining experimental and computational methods and exploring the material from the micro to the macroscale. In an exemplary manner, focusing on elastoplastic and viscoelastic aspects, the study

- provided comprehensive data about the macroscopic behavior of the material,

- delivered insight into microstructural effects controlling the macroscopic behavior,

- resulted in multiscale models, linking microscale and macroscale observations and providing estimates for macroscopic material properties,

- proposed computational strategies to enable investigations at a structural scale, and

- demonstrated the application of the models and computational strategies to practical examples in timber engineering.

As regards the elastoplastic behavior, multiscale modeling was applied in order to estimate macroscopic strength from microscale failure mechanisms. It could be shown that shear failure of lignin is responsible for a variety of macroscopic failure modes, from ultimate strengths in case of brittle failure in tension-dominated loading to elastic limit stresses in ductile failure in compression-dominated loading.

Strength predictions of the multiscale model were complemented by biaxial tests on spruce wood, which also delivered insight into the softening and hardening behavior of wood after reaching the elastic limit. In view of the pronounced anisotropy of the material, (at least) biaxial investigations are crucial for understanding the complex failure behavior. The tests displayed unexpectedly ductile behavior of wood, particularly at compressive loading perpendicular to the grain, which very much resembles the behavior of metals with a pronounced yield plateau.

A suitable description of this behavior in the framework of finite element computations was found in a multi-surface plasticity model. This model includes seven failure surfaces and associated softening and hardening rules. Such a complex formulation turned out necessary to reproduce adequately the behavior of a dowel-type connection, which is standardly used in timber engineering. The numerical simulations allowed to analyze internal stress and deformation distributions and the corresponding failure modes. This knowledge is crucial in order to improve current design rules for dowel-connections in timber engineering, enhancing efficiency and also reliability of their design.

As regards viscoelasticity, emphasis was laid on elucidating the microstructural mechanisms involved. A specially designed four-point-bending device, operated together with an X-ray diffraction device, enabled to study the immediate and delayed response of the cellulose crystallites during continuous loading in relation to the overall response of the sample at the macroscale. First results indicate an only minor contribution of these crystallites to the time and moisture-dependent response of wood.

Again multiscale modeling was applied in order to link these findings to macroscopic material properties. Exploitation of the correspondence principle enables to derive effective viscoelastic properties in the Laplace-Carson domain in exactly the same way, i.e. with the same upscaling relations, as for elastic properties.

Macroscopic tests completed the set of material properties for the time and moisture-dependent behavior of wood. They focused on the increased deformations upon moisture changes during continuous mechanical loading, referred to as mechanosorptive creep in wood technology. It could 
be shown that there is no difference between the material behavior at first wetting and subsequent wetting cycles, which had been a matter of debate for long in wood science.

Finally, the results of the multiscale model for the viscoelastic behavior of wood and of the additional macroscopic tests on mechanosorption were used to calibrate a phenomenological material model for the time- and moisture-dependent behavior of wood. Aiming at the implementation in a finite element code, a generalized Kelvin-Voigt model yields the most convenient and accurate description. This model is again applied to a typical task of timber engineering: The relaxation of production stresses in a beam of glued-laminated timber was assessed. Glued laminated timber products are facing increasing popularity in timber construction. Knowledge of the internal stresses is essential in order to set limit curvatures for the production and to come up with reliable results in the dimensioning process.

For most modeling tasks, both at material and structural level, experimental results were invoked for comparison with the model predictions in order to verify the suitability and predictive capability of the models. The only exception is the simulation of the stress relaxation in Glulam beams, where a comparison of numerical and experimental results was hindered by the lack of suitable test data.

Only the combination of efforts at different length scales and with complementary methods analytical, computational, and experimental - enabled to take a sufficiently broad view on the material wood and to come up with engineering solutions based on sound physical considerations. Main emphasis was laid on establishing the general framework and to provide examples for all fields of activities in terms of length scales and methods. Future research will deepen and extend the specific research presented herein. Being aware of the entire picture and of interrelations with other fields will enable to design the research accordingly and to optimize impact and relevance of the scientific activities.

\section{REFERENCES}

Armstrong, L. and Christensen, G. (1961). Influence of moisture changes on deformation of wood under stress. Nature, 191/4791, 869-870.

Armstrong, L. and Kingston, R. (1960). Effect of moisture changes on creep in wood. Nature, 185/4716, 862-863.

Armstrong, L. and Kingston, R. (1962). The effect of moisture content changes on the deformation of wood under stress. Australian Journal of Applied Science, 13/4, 257-276.

Back, E., Salmén, L., and Richardson, G. (1983). Transient effects on mechanical-properties of paper during sorption of moisture. Paperi Ja Puu - Paper And Timber, 65, 801.

Bader, T., Hofstetter, K., Hellmich, C., and Eberhardsteiner, J. (2011a). The poroelastic role of water in cell walls of the hierarchical composite 'softwood'. Acta Mechanica, 217, 75-100.

Bader, T., Hofstetter, K., Hellmich, C., and Eberhardsteiner, J. (2011b). Poromechanical scale transitions of failure stresses in wood: From the lignin to the spruce level. ZAMM - Zeitschrift für angewandte Mathematik und Mechanik, 90, 750-767.

Bardet, S. and Gril, J. (2002). Modelling the transverse viscoelasticity of green wood using a combination of two parabolic elements. Comptes Rendus Mecanique, 330, 549-556.

Bazant, Z. (1985). Constitutive equation of wood at variable humidity and temperature. Wood Science and Technology, 19, 159-177. 
Boyd, J. (1982). New perspectives in wood anatomy, chapter An anatomical explanation for viscoelastic and mechanosorptive creep in wood, and effects of loading rate on strength, pages 171-222. Martinus Nijhoff.

Colmar, J. (2011). Hygromécanique du matériau bois appliquée à la conservation du patrimoine culturel: étude sur la courbure des panneaux peints. Ph.D. thesis, Université de Montpellier 2, France.

Dormieux, L., Molinari, A., and Kondo, D. (2002). Micromechanical approach to the behavior of poroelastic materials. Journal of the Mechanics and Physics of Solids, 50, 2203-2231.

Eberhardsteiner, J. (1995). Biaxial testing of orthotropic materials using electronic speckle pettern interferometry. Measurement, 16, 139-148.

Eberhardsteiner, J. (2002). Mechanisches Verhalten von Fichtenholz. Springer-Verlag, Wien.

Eitelberger, J., Bader, T., Hofstetter, K., and Jäger, A. (2011). Multiscale prediction of viscoelastic properties of softwood under constant climatic conditions. Computational Materials Sience. submitted for publication.

Fengel, D., Wegener, G., and Wood, G. (1984). Wood - Chemistry, Ultrastructure, Reactions. De Gruyter, Berlin, New York, 2 edition.

Fioravanti, M., Sodini, N., and Navi, P. (2006). Investigation of the influence of hemicelluloses on time dependent behavior of wood. In M. Fioravanti and N. Macchioni, editors, Proceedings of the International Conference on 'Integrated Approach to Wood Structure, Behaviour and Applications', pages 190-195, Florence, Italy. DISTAF - University of Florence.

Geissler, G., Netzker, C., and Kaliske, M. (2010). Discrete crack path prediction by an adaptive cohesive crack model. Eng Fracture Mech, 77, 3541-57.

Gibson, L. J. and Ashby, M. F. (2001). Cellular solids - structure and properties. Cambridge University Press, Cambridge.

Grossman, P. (1976). Requirements for a model that exhibits mechano-sorptive behaviour. Wood Science and Technology, 10/3, 163-168.

Gurtin, M. and Sternberg, E. (1962). On the linear theaory of viscoelasticity. Archive for Rational Mechanics and Analysis, 11, 291-356.

Hanhijärvi, A. and Hunt, D. G. (1998). Experimental indication of interaction between viscoelastic and mechano-sorptive creep. Wood Science and Technology, 32/1, 57-70.

Hepworth, D. and Vincent, J. (1998). Modelling the mechanical properties of xylem tissues from tobacco plants (Nicotiana tabacum 'samsun') by considering the importance of molecular and micromechanics. Annals of Botany, 81, 761-770.

Hoffmeyer, P. and Davidson, R. (1989). Mechano-sorptive creep mechanism of wood in compression and bending. Wood Science and Technology, 23, 215-227.

Hofstetter, K., Hellmich, C., and Eberhardsteiner, J. (2007). Micromechanical modeling of solid-type and plate-type deformation patterns within softwood materials. a review and an improved approach. Holzforschung, 61, 343-351. 
Hofstetter, K., Hellmich, C., and Eberhardsteiner, J. (2008). Micromechanical estimates for elastic limit states in wood, revealing nanostructural failure mechanisms. Mechanics of Advanced Materials and Structures, 15, 474-484.

Hunt, D. G. (1984). Creep trajectories for beech during moisture changes under load. Journal of Materials Science, 19/5, 1456-1467.

Hunt, D. G. (1989). Linearity and non-linearity in mechano-sorptive creep of softwood in compression and bending. Wood Science and Technology, 23/4, 323-333.

Kollmann, F. (1982). Technologie des Holzes und der Holzwerkstoffe. Springer/Verlag, Berlin, Heidelberg, New York, second edition.

Liu, W., Belytschko, T., and Mani, A. (1986). Random field finite elements. International Journal for Numerical Methods in Engineering, 23, 1831-1845.

Lotfy, L., El-Osta, M., and Wellwood, R. (1972). Short-term creep as related to microfibril angle. Wood and Fiber Science, 4, 26-32.

Mackenzie-Helnwein, P., Müllner, H., Eberhardsteiner, J., and Mang, H. (2005). Analysis of layered wooden shells using an orthotropic elasto-plastic model for multi-axial loading of clear spruce wood. Computer Methods in Applied Mechanics and Engineering, 194, 2661-2685.

Mandel, J. (1966). Méchanique des milieux continus. Gauthier-Villars, Paris.

Matar, A. (2003). The mechano-sorptive creep of softwood in bending. Ph.D. thesis, Faculty of Engineering, Science and Technology, South Bank University, London, United Kingdom.

Montero, C. (2010). Caractérisation du comportement viscoélastique asymptotique du bois. Ph.D. thesis, Université de Montpellier 2.

Montero, C., Gril, J., Hunt, D., and Clair, B. (2011a). Influence of hygromechanical history on the longitudinal mechanosorptive creep of wood. Holzforschung, 66(6).

Montero, C., Clair, B., Alméras, T., van der Lee, A., and Gril, J. (2011b). Relationship between wood elastic strain under bending and cellulose crystal strain. Composites Science and Technology, 72(2).

Moss, W. (1984). On the computational significance of the strain space formulation of plasticity theory. Inter J Numer Methods Eng, 20, 1703-9.

Mukudai, J. (1983). Evaluation on non-linear viscoelastic bending deflection of wood. Wood Science and Technology, 17, 39-54.

Nakai, T., Yamamoto, H., and Nakao, T. (2005). The relationship between macroscopic strain and crystal lattice strain in wood under uniaxial stress in the fiber direction. Journal of Wood Science, 51, 193-194.

Nakai, T., Yamamoto, H., Nakao, T., and Hamatake, M. (2006). Mechanical behavior of the crystal lattice of natural cellulose in wood under repeated uniaxial tension stress in the fiber direction. Wood Science and Technology, 40, 683-695.

Nakano, T. (1999). Analysis of creep of wood during water adsorption based on the excitation response theory. Journal of Wood Science, 45, 19-23. 
Plaseied, A. and Fatemi, A. (2009). Tensile creep and deformation modeling of vinyl ester polymer and its nanocompsite. Journal of Reinforced Plastics and Composites, 28, 1775-1788.

Ranta-Maunus, A. (1975). The viscoelasticity of wood at varying moisture content. Wood Science and Technology, 9/3, 189-205.

Resch, E. and Kaliske, M. (2010). Three-dimensional numerical analyses of load-bearing behavior and failure of multiple double-shear dowel-type connections in timber engineering. Computers and Structures, 88, 165-177.

Saft, S. and Kaliske, M. (2011). Numerical simulation of the ductile failure of mechanically and moisture loaded wooden structures. Computers and Structures, 89, 2460-2470.

Schmidt, J. (2009). Modellierung und numerische Analyse von Strukturen aus Holz. Habilitationsschrift, Institut für Statik und Dynamik der Tragwerke, TU Dresden.

Schmidt, J. and Kaliske, M. (2007). Simulation of cracks in wood using a coupled material model for interface elements. Holzforschung, 61, 382-389.

Schmidt, J. and Kaliske, M. (2009). Models for numerical failure analysis of wooden structures. Engineering Structures, 31, 571-579.

Schniewind, A. and Barrett, J. (1972). Wood as linear orthotropic viscoelastic material. Wood Science and Technology, 6, 43-57.

Schniewind, A. P. (1968). Recent progress in the study of the rheology of wood. Wood Science and Technology, 2, 188-206.

Suquet, P. (1987). Elements of homogenization for inelastic solid mechanics. In E. Sanchez-Palencia and A. Zaoui, editors, Homogenization Techniques for Composite Media, pages 193-278, Wien, New York. Springer Verlag.

Suquet, P., editor (1997). Continuum Micromechanics. Springer Verlag, Wien, New York.

Suzuki, M. (1968). Mechanical deformation of crystal lattice of cellulose in Hinoki wood. Mokuzai Gakkaishi, 14, 268-275.

Suzuki, M. (1969). Relation between Young's modulus and the cell wall structures of Sugi (Cryptomeria japonica D. Don). Mokuzai Gakkaishi, 15, 268-275.

Tsai, S. W. and Wu, E. M. (1971). A general theory of strength for anisotropic matrials. Journal of Composite Materials, 5, 58-80.

Wagenführ, R. (2007). Holzatlas. Carl Hansen Verlag, München.

Zaoui, A. (2002). Continuum micromechanics: Survey. Journal of Engineering Mechanics, 128, 808-816.

Zimmermann, T., Sell, J., and Eckstein, D. (1994). Rasterelektronenmikroskopische Untersuchungen an Zugbruchflächen von Fichtenholz. Holz als Roh- und Werkstoff, 52, 223-229. 